\title{
Hydrothermally Reduced Graphene Hydrogel Intercalated with Divalent Ions for Dye Adsorption Studies
}

\author{
Alvin Lim Teik Zheng ${ }^{1}$, Supakorn Boonyuen ${ }^{2}$, Teruhisa Ohno ${ }^{3}$ and Yoshito Andou ${ }^{1,4, *(D)}$ \\ 1 Department of Life Science and Systems Engineering, Graduate School of Life Science and Systems Engineering, \\ Kyushu Institute of Technology, Fukuoka 808-0196, Japan; alvinltz29@gmail.com \\ 2 Department of Chemistry, Faculty of Science and Technology, Thammasat University, \\ Pathumthani 12120, Thailand; chemistrytru@gmail.com \\ 3 Department of Applied Chemistry, Faculty of Engineering, Kyushu Institute of Technology, \\ Fukuoka 804-8550, Japan; tohno@che.kyutech.ac.jp \\ 4 Collaborative Research Centre for Green Materials on Environmental Technology, Kyushu Institute of \\ Technology, Fukuoka 808-0196, Japan \\ * Correspondence: yando@life.kyutech.ac.jp
}

\section{check for}

updates

Citation: Zheng, A.L.T.; Boonyuen, S.; Ohno, T.; Andou, Y.

Hydrothermally Reduced Graphene Hydrogel Intercalated with Divalent Ions for Dye Adsorption Studies. Processes 2021, 9, 169. https:// doi.org/10.3390/pr9010169

Received: 10 December 2020

Accepted: 13 January 2021

Published: 18 January 2021

Publisher's Note: MDPI stays neutral with regard to jurisdictional claims in published maps and institutional affiliations.

Copyright: (c) 2021 by the authors. Licensee MDPI, Basel, Switzerland. This article is an open access article distributed under the terms and conditions of the Creative Commons Attribution (CC BY) license (https:/ / creativecommons.org/licenses/by/ $4.0 /)$.

\begin{abstract}
Fundamental studies involving divalent ion intercalated graphene-based hydrogel are still lacking in terms of their adsorption behavior towards dye pollutants. In this study, we prepared a self-assembled $\mathrm{Mg}^{2+}$ and $\mathrm{Ca}^{2+}$ intercalated reduced graphene hydrogel $(\mathrm{rGH})$ using hydrothermal treatment to evaluate the intercalation impact on the adsorption capability towards cationic dyes, methylene blue and rhodamine B. The morphological, structural, thermal, and textural properties of the divalent ion intercalated reduced graphene hydrogels were studied using Fourier transform infrared spectrometer, thermogravimetric analysis, Raman spectroscopy, scanning electron microscope-energy dispersive spectroscopy, X-ray photoelectron spectroscopy, Brunauer-EmmettTeller surface area analysis, and X-ray diffraction. The increased adsorption capacity of the divalent ion intercalated reduced graphene-based hydrogels towards the dye molecules resulted from the increase in the specific surface area and pore volume due to the $\mathrm{Mg}^{2+}$ and $\mathrm{Ca}^{2+}$ bridging that formed spaces between the graphene sheets framework. Adsorption kinetics and the equilibrium adsorption isotherm were fitted by a pseudo-second-order alongside intraparticle diffusion kinetic models and Langmuir isotherm respectively. In addition, the divalent ion intercalated reduced graphene hydrogel showed good generation after three cycles of simultaneous adsorption.
\end{abstract}

Keywords: graphene hydrogel; hydrothermal; dye adsorption; calcium; magnesium

\section{Introduction}

Water bodies contaminated with dye-containing effluent disposed from various industries such as textile and printing often contribute to massive environmental and health problems [1-4]. Currently, the treatment of dye wastewater includes biological treatment, coagulation, floatation, and adsorption. Due to the low cost, ease of operation, and high performance, adsorption is often preferred for dye removal from waste water [5-8]. For the past years, many significant findings on the remediation of dye wastewater via adsorption have been reported using graphene-based nanomaterials upon comparing to other carbon-based materials such as biochar, activated carbon, etc. [9-12].

From the carbon family, graphene possessed a honeycomb crystal lattice composing of hexagonally $\mathrm{sp}^{2}$ hybridized carbon atom with a thickness of equal to one atom diameter [13]. This two-dimensional (2D) material has gained prominence among researchers due to its unique properties such as possessing high surface area $\left(2600 \mathrm{~m}^{2} / \mathrm{g}\right)$, intrinsic electron mobility (200,000 cm²/Vs), Young's Modulus (1 TPa), and high thermal conductivity $(5000 \mathrm{~W} / \mathrm{mK})$ [14-16]. Graphene oxide (GO) is a commonly used precursor in the synthesis of graphene. Until now, the salient properties associated with 2D graphene have 
not yet been realized due to the fact that they cannot exist in a free state due to aggregation of the sheets from the intrinsic $\pi-\pi$ [17]. In wastewater remediation applications, the usage of graphene-based powder complicates the post-recovery process which is not ideal in large scale applications. The development of three-dimensional (3D) graphene-based architecture such as hydrogels or aerogels has become a promising choice to tackle the aforementioned drawbacks. The 3D reduced graphene hydrogel block morphology explicitly tackles the issue of easy recovery and prevents the release of graphene nanosheets from contributing to secondary contamination [18]. The intrinsic $\pi-\pi$ interactions and van der Waals interactions drive the hydrogel formation between the sheets to achieve macroscopic structural stability $[19,20]$. The three-dimensional graphene framework contains an interconnected porous structure with a large specific surface area making them ideal for wastewater treatment $[21,22]$. In addition, reduced graphene-based hydrogels can act as a templating material for the inclusion/blending with small molecules, metal/metal oxide nanoparticles, polymer complex, etc. which enable the design of novel multi-functional hydrogels with upgraded properties $[23,24]$. In term of pollution remediation, reduced graphene hydrogel form $\pi-\pi$ interactions with adsorbate molecules containing aromatic rings. Furthermore, remaining oxygenated groups on their surface enables electrostatic, van der Waals forces, and hydrogen bonding interactions with the pollutants such as small dyes [25]. Previously, ample studies have been conducted using graphene-based hydrogel as promising adsorbent material for wastewater dye remediation [26-32]. To date, various approaches were reported in the successful fabrication of reduced graphene-based hydrogels which include hydrothermal treatment [20,33-35], solvothermal method and chemical vapor deposition (CVD) [36]. Inherently, the hydrothermal process is a preferred alternative as it is a scalable approach that enables the control in the size and properties of the hydrogel from operating parameters such as hydrothermal time and hydrothermal temperature [37]. In addition, the process eliminates the usage of reducing agent, which significantly reduced the cost [38]. During the hydrothermal process, superheated water acts as strong electrolyte with high diffusion and dielectric constant; hence readily catalyzes bond cleavage of oxygen moieties present on the basal planes of the graphene sheets [39].

Previously, Jiang et al. [40] compared divalent ion $\left(\mathrm{Ca}^{2+}, \mathrm{Ni}^{2+}\right.$, and $\left.\mathrm{Co}^{2+}\right)$ linkage between graphene sheets in a 3D architecture prepared via hydrothermal treatment. They found that the graphene sheet is interconnected via chemical and hydrogen bonds, which are driven by water molecules, divalent ions, and oxygen-functional groups on the reduced graphene sheet. The inclusion of calcium ions is also reported to improve the mechanical performance of alginate/graphene-based hydrogel due to the formation of different microcosmic morphologies within the framework [41,42].

In energy applications, $\mathrm{Ca}^{2+}$ forms bridges between graphene sheets; hence creating new electron energy levels and conduction channels [43]. The comparison between alkali metal ions as crosslinkers should be made to reduce the knowledge gap in order to fully grasp their effect on the physical and chemical properties of the hydrogels synthesized. Taking the unique behavior of reduced graphene hydrogel, herein, we describe a simple one-pot synthesis via hydrothermal treatment of GO in the presence of $\mathrm{Mg}^{2+}$ and $\mathrm{Ca}^{2+}$ for the preparation of divalent-ion intercalated reduced graphene hydrogels (rGH). The effect of divalent metal ion cross-linking within the 3D macrostructure is accessed for their adsorption behavior towards methylene blue $(\mathrm{MB})$ and rhodamine $\mathrm{B}(\mathrm{RhB})$. The findings of this study will provide useful insights on future works pertaining to intercalated reduced graphene hydrogel practical applications in dye wastewater treatment.

\section{Materials and Methods}

\subsection{Materials, Reagents, and Equipment}

Graphene oxide (GO) dispersion in water (0.1-2.0\%) was used as received from Nippon Shokubai Co., Ltd. (AX-1-FM-W-151). Magnesium chloride $\left(\mathrm{MgCl}_{2}\right)$, calcium chloride $\left(\mathrm{CaCl}_{2}\right)$, methylene blue $(\mathrm{MB})$, rhodamine $\mathrm{B}(\mathrm{RhB})$, hydrochloric acid $(\mathrm{HCl})$ was obtained from Wako Pure Chemical Industries Ltd., Japan. Deionized water $(18.25 \mathrm{M} \Omega \mathrm{cm})$ 
produced by a Milli-Direct 16 (MilliporeSigma, Burlington, MA, USA) was used for the entire experiment. All the reagents and materials were used without further purification unless otherwise specified. For the sonication process, a bath ultrasonicator (AS ONE Ultrasonic Cleaner Single Frequency, 3L (MSC-3) 40 kHz, $100 \mathrm{~W}$ ) was used as described below.

\subsection{Synthesis of Divalent Ion Intercalated Reduced Graphene Hydrogel}

Briefly, $30 \mathrm{~mL}$ of GO solution was prepared by the sonication of GO dispersion in deionized water to a concentration of $2 \mathrm{mg} / \mathrm{mL}$ for $1.5 \mathrm{~h}$ in order to exfoliate the graphene sheets. $10 \mathrm{~mL}$ of $0.01 \mathrm{M} \mathrm{MgCl}_{2}$ and $\mathrm{CaCl}_{2}$ was added into the $\mathrm{GO}$ solution, respectively and stirred for $15 \mathrm{~min}$. The solution mixture was then transferred into an $80 \mathrm{~mL}$ modified autoclave glass bottle and sealed. The hydrothermal reduction was carried out in a TOMY LBS-325 high-pressure steam sterilizer (TOMY Seiko Co., Ltd., Tokyo, Japan) at $130{ }^{\circ} \mathrm{C}$ for $8 \mathrm{~h}$. Scheme 1 depicts the schematic representation for the formation of divalent ion intercalated reduced graphene hydrogel. The resulting reduced graphene hydrogels (rGH) were then dialyzed in $\mathrm{H}_{2} \mathrm{O}$ for $24 \mathrm{~h}$. The obtained rGHs were denoted as $\mathrm{rGH}-\mathrm{Mg}$ and rGH$\mathrm{Ca}$ to ease identification. The hydrothermal treatment of GO solution $(40 \mathrm{~mL})$ without the addition of divalent salt was also carried out and denoted as rGH. The rGH samples were then freeze-dried at $-50{ }^{\circ} \mathrm{C}$ for $24 \mathrm{~h}$ to remove any moisture content without destroying the $3 \mathrm{D}$ macrostructure. The freeze-dried rGHs were kept for characterization studies as described below.

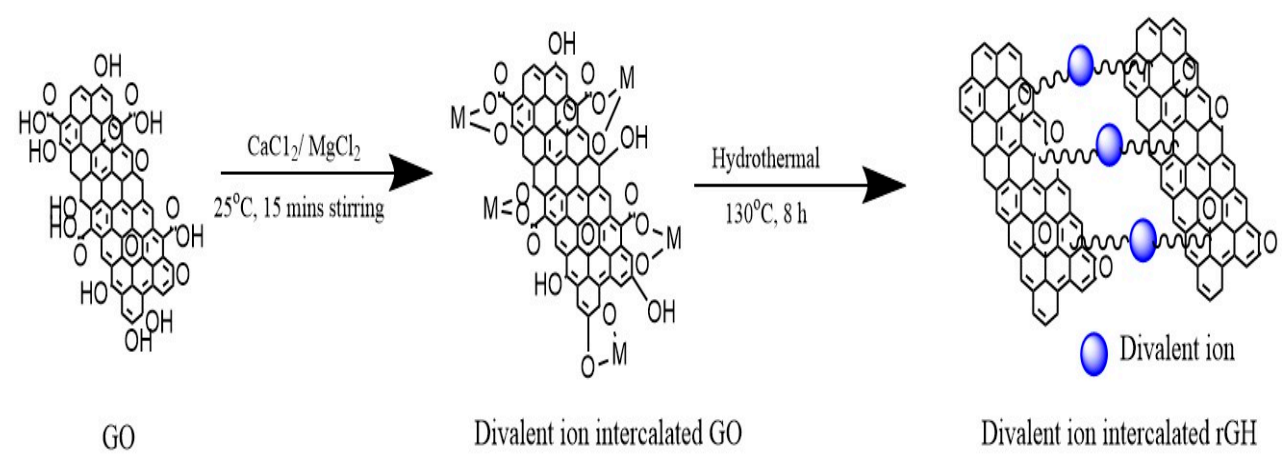

Scheme 1. The schematic representative of the formation of divalent ion intercalated reduced graphene hydrogel without taking into account the interactions occurred for the formation of hydrogel.

\subsection{Characterizations}

The absorption spectrum of the colloidal suspension of individual GO and with the presence of $\mathrm{MgCl}_{2}$ and $\mathrm{CaCl}_{2}$ were measured by UV-vis spectrophotometer (Genesys 10s, Thermo Fisher Scientific, Waltham, MA, USA). The zeta potential and particle size analysis of the colloidal suspension were determined using DelsaMax Pro (Beckman Coulter, Inc., Brea, CA, USA). The morphology of the freeze-dried hydrogels was accessed using JEOL 6000 microscope (JEOL Ltd., Tokyo, Japan) scanning electron microscopy (SEM) attached with energy dispersive X-ray analyzer (EDX) operated at $10 \mathrm{kV}$ accelerating voltage. The crystalline structure was recorded on a Rigaku X-ray diffractometer with $\mathrm{Cu} \mathrm{K}$ - $\alpha$ radiation at $40 \mathrm{kV}$ and $15 \mathrm{~mA}$ with a scan rate of $10^{\circ} / \mathrm{min}$. Attenuated total reflectance Fourier transform infrared (ATR-FTIR) spectroscopy was carried out on a Nicolet iS5 (Thermo Fisher Scientific, Madison, WI, USA) spectrometer. Thermogravimetric analysis (TGA) was performed on an EXSTAR TG/DTA7000 (Hitachi High-Tech, Tokyo, Japan) under continuous $\mathrm{N}_{2}$ stream. Raman spectroscopy measurements were performed using JASCO NRS-5100 Laser Raman Spectrometer (JASCO International Co., Ltd., Tokyo, Japan) with an excitation wavelength of $532 \mathrm{~nm}$ and $2.5 \mathrm{~mW}$ laser power beam. The $\mathrm{I}_{\mathrm{D}} / \mathrm{I}_{\mathrm{G}}$ ratio was automatically calculated using the Spectra Manager II software (JASCO International Co., Ltd., Tokyo, Japan) pre-installed after performing wavenumber correction and intensity correction. X-ray photoelectron spectroscopy (XPS) was performed on an Axis Nova (XPS) Surface 
Analyzer (Kratos Analytical Ltd, Manchester, UK) with a monochromatized Al K $\alpha$ X-ray source. The XPS spectra were analyzed for their relative atomic percentages of the element species present using the CasaXPS program (Version 2.3.22rev1.0I, Casa Software Ltd., Teignmouth, UK). The peaks are fitted by Gaussian-Lorentzian (GL) formula fitted with a Shirley background. $\mathrm{N}_{2}$ adsorption-desorption studies were carried out using a Surface Area and Pore Size Analyzer (Quantachrome Instruments, Boynton Beach, FL, USA). The surface area and pore size distribution of the rGH samples were calculated using the Brunauer-Emmett-Teller (BET) method via $\mathrm{N}_{2}$ adsorption-desorption isotherms and the Barrete-Joynere-Halenda (BJH) method, respectively.

\subsection{Adsorption Experiments}

Analytical grade dyes, cationic methylene blue (MB), and rhodamine B (RhB) were used as model pollutants for the adsorption experiment at room temperature in order to probe the adsorption performance of the hydrogels. The as-prepared hydrogels were placed into $20 \mathrm{mg} / \mathrm{L}, 150 \mathrm{~mL}$ dye solution, and agitated until adsorption-desorption equilibrium is achieved. For each experimental run, $2 \mathrm{~mL}$ of the dye solution was removed at a specific time interval and centrifuged at $2000 \mathrm{rpm}$ for $5 \mathrm{~min}$ to remove suspended particles before residue dye absorbance measurements were taken. From Supplementary Figure S1, the residual concentration of the $\mathrm{MB}$ and $\mathrm{RhB}$ were computed from the calibration curve prepared by measuring the absorbance at various concentrations of the dye at 664 and 554 $\mathrm{nm}$, respectively. The adsorption capacity $\left(Q_{e}\right)$ for the hydrogels were calculated using the following equation:

$$
Q_{e}=\frac{\left(C_{0}-C_{t}\right) V}{m}
$$

where $C_{0}$ represents the initial concentration $(\mathrm{mg} / \mathrm{g}), C_{t}$ represents the equilibrium concentration at the specific time $(\mathrm{mg} / \mathrm{g}), V$ is the volume of the dye solution $(\mathrm{L})$ and $\mathrm{m}$ is the mass of the adsorbent (mg). Three kinetic models, namely pseudo first-order (PFO), pseudo second-order (PSO) and Elovich were used to understand the adsorption kinetics of the MB and RhB adsorption. PFO corresponded to a diffusion-controlled process in a solid-liquid phase. PSO assumed the process is controlled by adsorption reaction at a liquid-solid interface. Elovich model was applied to describe the adsorption in a non-ideal state. The model assumes that the rate of solute adsorption decreases exponentially as the amount of adsorbed solute increases. The models' equation can be described as follows:

The pseudo first-order (PFO) model:

$$
\ln \left(Q_{e}-Q_{t}\right)=\ln Q_{e}-\frac{K_{1} t}{2.303}
$$

The pseudo second-order (PSO) model:

$$
\frac{t}{Q_{t}}=\frac{1}{K_{2} Q_{e}^{2}}+\left(\frac{1}{Q_{e}}\right) t
$$

The Elovich model:

$$
Q_{t}=\frac{1}{\beta} \ln \alpha \beta+\frac{1}{\beta} \ln t
$$

where $Q_{e}$ and $Q_{t}$ are the dye amount adsorbed at equilibrium (mg/g), $k$ represents the time, $K_{1}\left(\mathrm{~h}^{-1}\right)$ or $K_{2}(\mathrm{~g} / \mathrm{mg} \mathrm{h})$ refers to the adsorption rate constant, $\alpha$ is the initial adsorption rate $(\mathrm{mg} / \mathrm{g})$ and $\beta$ is the desorption coefficient $(\mathrm{mg} / \mathrm{g})$. To further confirm the diffusion mechanism process, the intraparticle diffusion (IPD) model was also applied and can be written as:

$$
Q_{t}=K_{p} t^{1 / 2}+C
$$

where $K_{p}$ is the rate constant of the intraparticle diffusion kinetic model, $C$ is the thickness of the boundary layer. 
The Langmuir, Freundlich, and Temkin adsorption isotherms were applied in the process to probe the adsorption process by fitting the equilibrium data. The Langmuir model presumes monolayer adsorption onto a homogenous adsorbent surface with the idea that energy change is uniform for all adsorption. On the other hand, the Freundlich model assumes that multilayer adsorption occurs on a heterogeneous surface. On the other hand, the Temkin model assumes that the heat of adsorption decreases linearly instead of logarithmically with the increase in the surface coverage and that adsorption can be characterized by uniform binding energies. The linear form of the equation employed to describe the adsorption isotherm is as follows:

Langmuir isotherm model:

$$
\frac{C_{e}}{Q_{e}}=\frac{1}{K_{L} Q_{m}}+\frac{C_{e}}{Q_{m}}
$$

Freundlich isotherm model:

$$
\ln Q_{e}=\ln K_{F}+\frac{1}{n} \ln C_{e}
$$

Temkin isotherm model:

$$
Q e=\frac{R T}{B} \ln K_{T}+\frac{R T}{B} \ln C_{e}
$$

where $C_{e}$ is the equilibrium concentration of the dye solution $(\mathrm{mg} / \mathrm{L}) . Q_{e}$ and $Q_{m}$ are the adsorption capacity ( $\mathrm{mg} / \mathrm{g}$ ) adsorbed on the adsorbent at equilibrium and maximum adsorption capacity $(\mathrm{mg} / \mathrm{g})$, respectively. $K_{L}$ is the Langmuir binding constant $(\mathrm{L} / \mathrm{mol})$, $K_{F}$ is the Freundlich binding constant $(\mathrm{L} / \mathrm{mol}), K_{T}$ is the equilibrium binding constant $(\mathrm{L} / \mathrm{mol})$ corresponding to maximum binding energy and $1 / \mathrm{n}$ is the adsorption intensity. $B$ is related to the heat of adsorption $(\mathrm{J} / \mathrm{mol}), R$ is the universal gas constant $(8.314 \mathrm{~J} / \mathrm{K} . \mathrm{mol})$, and $T$ is the absolute temperature $(\mathrm{K})$.

\section{Results}

\subsection{Characterization of GO Colloidal Suspension in the Presence of Divalent Ions}

Before hydrothermal reaction, the addition of $\mathrm{MgCl}_{2}$ and $\mathrm{CaCl}_{2}$ into the $\mathrm{GO}$ suspension led to the intercalation between the divalent atoms and the oxygen-containing functional groups occurring between the basal plane and edges; hence leading to a network of continuous bridging $[44,45]$. The divalent ions $\left(\mathrm{M}^{2+}\right)$ may interact with $\mathrm{GO}$ sheets via two different binding modes. The strongest binding mode is the $\mathrm{M}^{2+}$ ions bound to the carboxylic group at the edges which results in the cross-linking with neighbouring sheets. The second, from the creation of $\mathrm{C}-\mathrm{OH}$ due to the ring-opening epoxide by $\mathrm{M}^{2+}$ which facilitates the intercalation of metal ions into the gallery between GO sheets [45]. In order to probe the interaction with the divalent ions, UV-visible analysis was conducted on the GO suspension which is shown in Supplementary Figure S2. The UV-Vis spectrum of GO suspension after sonication showed two distinct bands, a maximum at $262 \mathrm{~nm}$ attributed to $\pi-\pi^{*}$ transition of the aromatic C-C bonds, and the shoulder peak at $302 \mathrm{~nm}$ corresponds to the $n-\pi^{*}$ transition of the carbonyl $C=O$ bonds [46]. The decrease in intensity of the shoulder peak and also the slight blue shift could be possible from the intercalation of the divalent ion with the oxygen-containing functional groups. Saha et al. [47] found the blue shifting upon studying the effect of anionic surfactant (SDS) intercalation on GO. From Table 1, the addition of the neutral salt solution of $\mathrm{MgCl}_{2}$ and $\mathrm{CaCl}_{2}$ does not bring significant changes to the $\mathrm{pH}$ of the GO suspension. To further confirm the intercalation behaviour and access the colloidal stability, DLS and zeta potential studies were conducted. The increase in the lateral size of the GO and also the increase in zeta potential value after the inclusion of the divalent ion in the GO suspension indicated that $\mathrm{Mg}^{2+}$ and $\mathrm{Ca}^{2+}$ showed good affinity towards the oxygen functional groups GO sheets are highly negative charged which is attributed to the ionization of oxygen-containing functional groups present at 
the basal and planar plane. We posit that the higher particle diameter obtained for rGH$\mathrm{Ca}$ is attributed to the larger ionic size of $\mathrm{Ca}^{2+}$ for easier chelation with the oxygenated group of the GO [48]. The higher hydration energy of $\mathrm{MgCl}_{2}$ led to the greater volumetric dimension of its hydrated ion which may limit their interactions via ionic cross-linking with the negatively charged GO sheets [49]. Zeta potential values below (more negative) than $-30 \mathrm{mV}$ are considered ideal to represent sufficient electrostatic repulsion to ensure a stable dispersion [50]. The more positive zeta potential values obtained for the colloidal suspension of $\mathrm{GO}$ in the presence of divalent ion occurs due to the lower charge density of GO from the interaction with negatively charged functional groups.

Table 1. Properties of the GO colloidal suspension in the presence of $\mathrm{MgCl}_{2}$ and $\mathrm{CaCl}_{2}$.

\begin{tabular}{cccc}
\hline Sample & pH & Diameter $(\mathbf{n m})$ & Zeta Potential (mV) \\
\hline $\mathrm{GO}$ & 2.70 & 2015.2 & -39.24 \\
$\mathrm{GO}+\mathrm{MgCl}_{2}$ & 2.69 & 4563.3 & -36.63 \\
$\mathrm{GO}+\mathrm{CaCl}_{2}$ & 2.69 & 7680.9 & -32.37 \\
\hline
\end{tabular}

Supplementary Figure S3 depicts the hydrogels after freeze-drying process which showed the retainment of the cylindrical monolith reduced graphene hydrogel in the presence of the $\mathrm{Mg}^{2+}$ and $\mathrm{Ca}^{2+}$. The surface of the reduced graphene hydrogel after freeze dry becomes hydrophobic [51,52]. From previously reported studies, the freeze-drying process removed water molecules embedded in the pore structure, which leads to the collapse of the framework due to $\pi-\pi$ interactions between the graphene sheets. It can be seen that the presence of $\mathrm{Mg}^{2+}$ and $\mathrm{Ca}^{2+}$ introduced in the graphene framework preserved the cylindrical structure of the hydrogel. It is posited that the divalent ion bridged the individual graphene sheets; hence retaining the hydrogel structure.

\subsection{Characterization of Freeze-Dried Hydrogels}

Figure 1 depicts SEM images of the freeze-dried GO and the reduced graphene hydrogels. GO possesses a wrinkled surface topography and a disorderly manner as depicted in Figure 1a which can be attributed to the deviation from the $\mathrm{sp}^{2}$ planar character of the carbon atom. Based on Figure 1b-d, the morphology of rGHs clearly depicted a randomly oriented 3D framework after hydrothermal treatment. The reduced graphene nanosheets are of aggregated crumples nanosheets which were similar to previous literature obtained via hydrothermal treatment [39]. The aggregation of reduced graphene sheets is attributed to the increased hydrophobic interactions between individual sheets. The intercalation of the divalent ion may occur electrostatically in which the ion coordinates with the carboxylic groups; hence forming linkages between the reduced graphene sheets. In the situation in which the carboxylic groups are saturated, electrostatic repulsion between other carboxylic groups is reduced, leaving the system to interact through the $\pi=\pi$ bond network which drives the stacking [53]. The intercalation of $\mathrm{Mg}^{2+}$ and $\mathrm{Ca}^{2+}$ can be roughly accessed from the atomic elemental composition from the EDX signals assigned to $\mathrm{Mg}$ and Ca. Even though the peak signal is relatively low $(<1 \%$ atomic percentage), the inclusion of the divalent ion altered the morphology in terms of the introduction of more pore cavities.

The elemental analysis of the commercial GO as well as the rGHs samples were summarized in Table 2. The presence of trace amount of $\mathrm{S}$ and $\mathrm{K}$ in the commercial GO sample may be attributed to the residue reactants used during the manufacturing process. The $\mathrm{C} / \mathrm{O}$ atomic percentage (at \%) of GO, rGH, rGH-Mg, and $\mathrm{rGH}-\mathrm{Ca}$ is $1.40,3.05,3.27$, and 3.41, respectively. The slight increase in the $\mathrm{C} / \mathrm{O}$ ratio indicates that the intercalation of $\mathrm{Mg}^{2+}$ and $\mathrm{Ca}^{2+}$ further assisted in the removal of the oxygenated functional groups during the hydrothermal treatment. The result of the intercalation of the divalent ion creates $\mathrm{C}-\mathrm{OH}$ from the to the ring opening epoxide which can be directly desorbed from the graphene sheet due to Coulomb repulsion derived from the extra charge accumulation [54]. Hence, the rearrangement of aromatic $\mathrm{sp}^{2}$ carbon resulted in higher $\mathrm{C} / \mathrm{O}$ ratio for the divalent ion intercalated hydrogels. The difficulty of $\mathrm{Mg}^{2+}$ intercalation in comparison to $\mathrm{Ca}^{2+}$ can be 
attributed to the strong electrostatic forces between the $\mathrm{Mg}$ ions and the negatively charged groups on the graphene sheet which induce the intrinsically slow kinetics of ion insertion and diffusion [55].

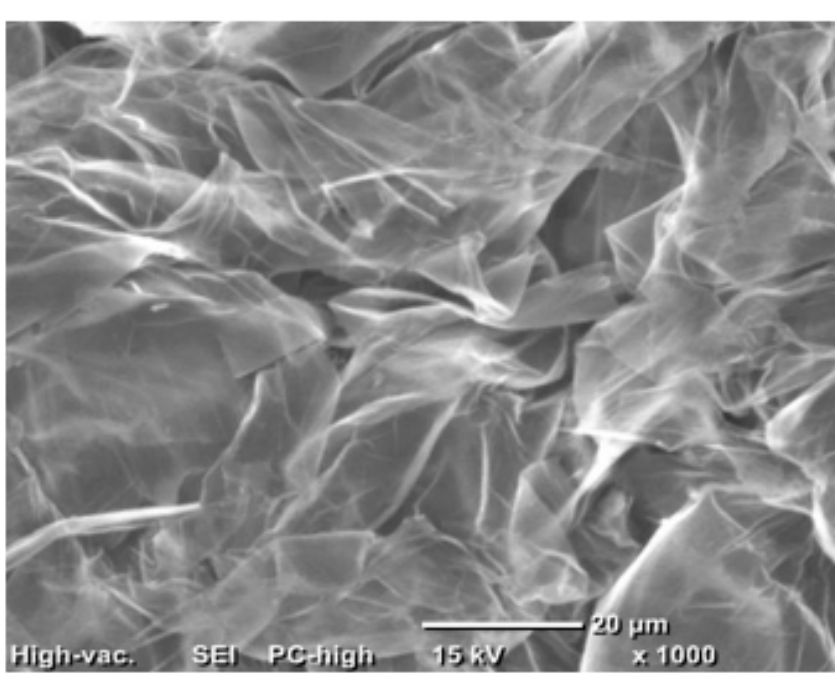

(a)

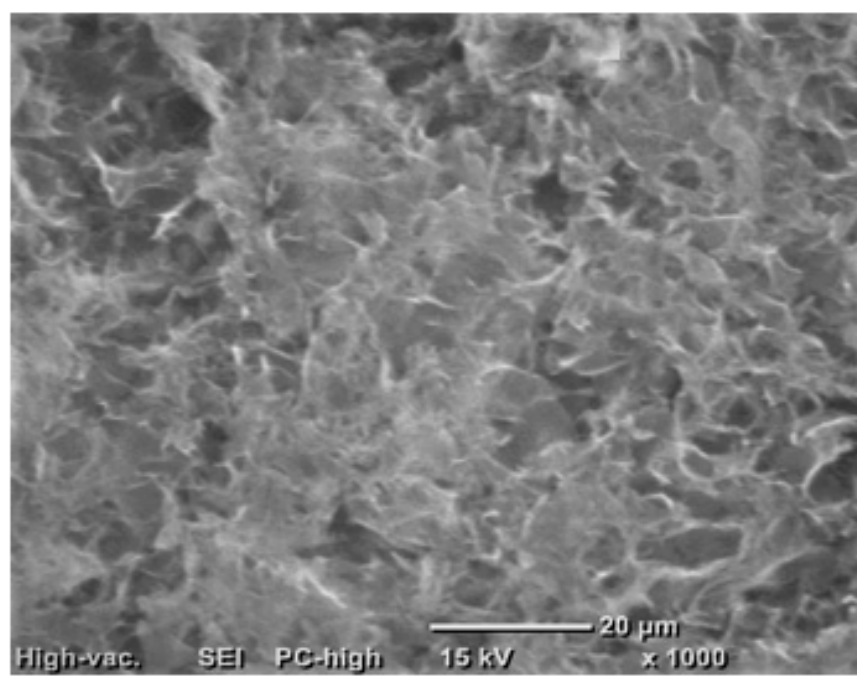

(c)

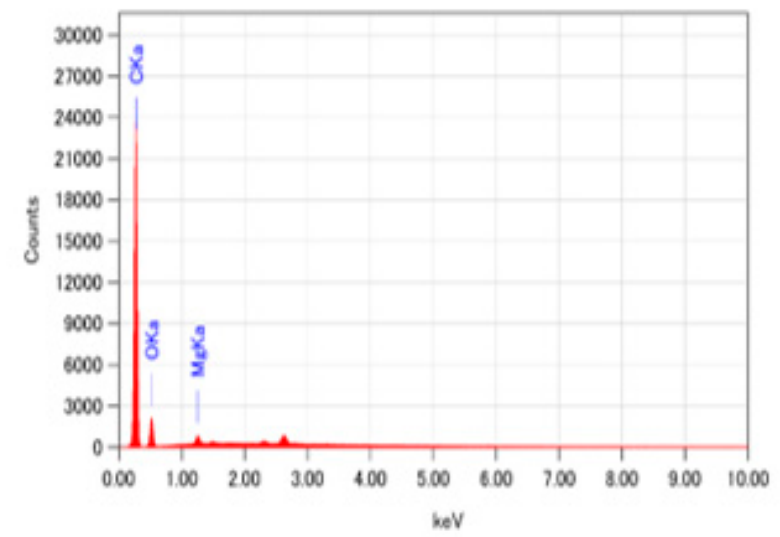

(e)

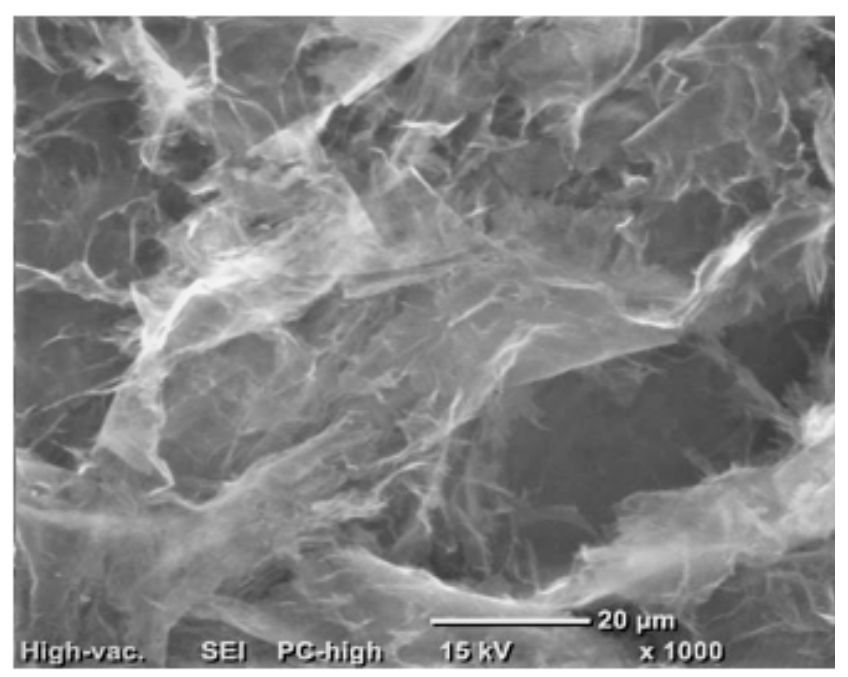

(b)

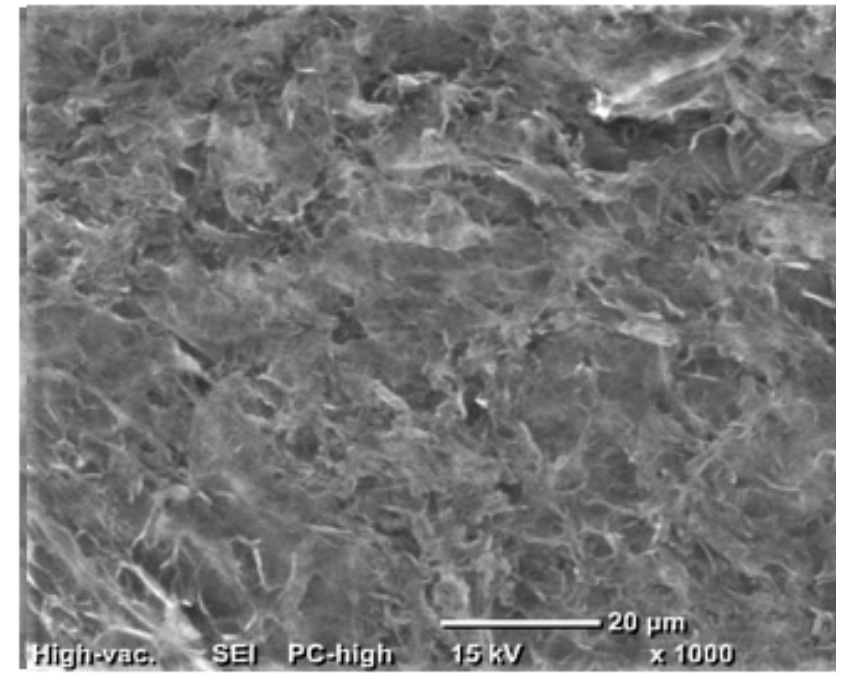

(d)

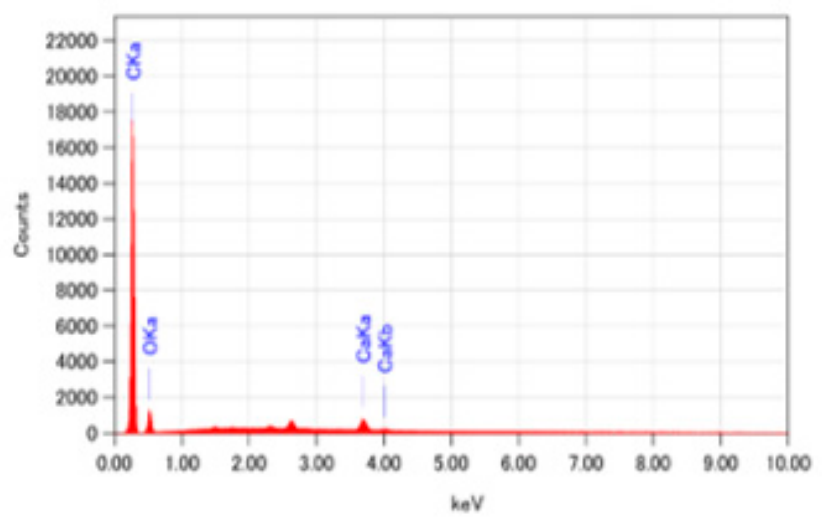

(f)

Figure 1. Scanning electron microscopy (SEM) images of freeze dried (a) graphene oxide (GO), (b) reduced graphene hydrogels (rGH), (c) rGH-Mg, (d) rGH-Ca. EDX spectrum with elemental distribution for (e) rGH-Mg and (f) rGH-Ca. 
Table 2. Elemental composition of GO, rGH, rGH-Mg and rGH-Ca obtained from EDX analysis.

\begin{tabular}{cccccccc}
\hline Sample & $\mathbf{C ~ ( \% )}$ & $\mathbf{O}(\mathbf{\%})$ & $\mathbf{S ~ ( \% )}$ & $\mathbf{K ~ ( \% )}$ & $\mathbf{M g} \mathbf{( \% )}$ & $\mathbf{C a}(\mathbf{\%})$ & Total (\%) \\
\hline GO & 55.99 & 39.82 & 3.81 & 0.38 & 0.00 & 0.00 & 100.00 \\
rGH & 75.31 & 24.69 & 0.00 & 0.00 & 0.00 & 0.00 & 100.00 \\
rGH-Mg & 76.15 & 23.28 & 0.00 & 0.00 & 0.57 & 0.00 & 100.00 \\
rGH-Ca & 76.74 & 22.49 & 0.00 & 0.00 & 0.00 & 0.77 & 100.00 \\
\hline
\end{tabular}

The interlayer spacing of GO and the freeze-dried hydrogels were confirmed using powder X-ray diffraction (XRD). From Figure 2a, the diffractogram of the commercial freeze-dried GO exhibited a sharp peak at $7.25^{\circ}$ corresponding to the characteristic carbon peak ( $\left.\begin{array}{lll}0 & 0 & 1\end{array}\right)$ with a d-spacing of $1.21 \mathrm{~nm}$. The larger d-spacing obtained from GO upon comparing to other previous reported findings [56] $(\sim 0.80 \mathrm{~nm})$ could be attributed to the freeze-drying process that retains the graphene framework. The d-spacing of the most intense peak was calculated by using Bragg's equation, which is presented as:

$$
n \lambda=2 d \sin \theta
$$

where $n$ is an integer, $\lambda$ is the $\mathrm{X}$-ray wavelength and $\theta$ is the angle between incidence and reflected rays. The reduction of GO led to the disappearance of the $\left(\begin{array}{lll}0 & 0 & 2\end{array}\right)$ peak and appearance of a well-resolved diffraction peak observed at $24.02^{\circ}, 24.74^{\circ}$, and $23.56^{\circ}$ corresponding to d-spacing values of $0.370,0.360$, and $0.362 \mathrm{~nm}$ for $\mathrm{rGH}, \mathrm{rGH}-\mathrm{Mg}$, and rGH-Ca, respectively. The finding indicated that GO has been successfully reduced to its ${ }^{\prime}$ reduced form via hydrothermal treatment. The intercalation of the divalent ion resulted in reduced interlayer spacing in comparison to $\mathrm{rGH}$. The presence of small diffraction peaks, $2 \theta$ at $\sim 43.0-44.0^{\circ}$ is related to the $\left(\begin{array}{lll}1 & 0 & 2\end{array}\right)$ plane of reduced graphene structure. Hence, the inclusion of intercalated $\mathrm{Mg}^{2+}$ and $\mathrm{Ca}^{2+}$ between the graphene layers led to the decrease in the interlayer spacing, making the sheets packed tightly against eachanother, which signified the intercalation of the divalent ions into the graphene framework.

FTIR provided an overview of the presence of chemical functionalities in the freezedried hydrogels. Figure $2 \mathrm{~b}$ depicts the ATR-FTIR spectra of GO, rGH, rGH-Mg, and rGH-Ca. The spectrum of GO with following peaks: $1080 \mathrm{~cm}^{-1}$ corresponded to C-O (alkoxy group), $1280 \mathrm{~cm}^{-1}$ (epoxy group), $1618 \mathrm{~cm}^{-1}$ associated with the presence of $\mathrm{C}=\mathrm{C}$ (aromatic), and $1750 \mathrm{~cm}^{-1}$ assigned to $\mathrm{C}=\mathrm{O}$ (carboxyl group) present mostly along the sheet and basal plane. The broad peak at $3212 \mathrm{~cm}^{-1}$ originated from the hydroxyl O-H bond. The hydrothermal reduction of the GO led to the significant weakening of the O-H and $\mathrm{C}=\mathrm{O}$ peaks and is apparent in the $\mathrm{Mg}^{2+}$ and $\mathrm{Ca}^{2+}$ intercalated reduced graphene hydrogels Moreover, the intense weakening of alkoxyl groups $\left(1040 \mathrm{~cm}^{-1}\right)$ and the epoxy groups for the divalent ion intercalated samples indicated possible interaction with the groups. The peak at about $1550 \mathrm{~cm}^{-1}$ confirmed the restoration of the $\mathrm{sp}^{2}$ carbon network while the peak at around $1710 \mathrm{~cm}^{-1}$ corresponded to vibrations of carbonyl groups. Hence, the intercalation is posited to occur from the interaction of the divalent ion to the carboxylic group which is linked to the neighbouring sheet. The intercalation in between the graphene sheets also may occur from the ring-opening epoxide by the divalent ions. Similar result corroborated the study by Park et al. [45], in which the epoxy/ether C-O stretch significantly decreased after exposure to Lewis acidic divalent metal ions leading to the ring opening of the epoxide.

Raman spectroscopy characterization was carried out to access the intercalation effect of $\mathrm{Mg}^{2+}$ and $\mathrm{Ca}^{2+}$ towards the defects and disorder within the graphene sheet structure. The Raman spectra of GO, rGH, rGH-Mg, and rGH-Ca is depicted in Figure 2c. The two characteristics bands of GO located at 1392 and $1596 \mathrm{~cm}^{-1}$ were assigned to the D and G band, respectively. The $\mathrm{D}$ band is assigned to the breathing mode of $\mathrm{k}$ point phonons with $\mathrm{A}_{1 \mathrm{~g}}$ symmetry and band attributed to the $\mathrm{sp}^{3}$ hybridization of carbon; $\mathrm{G}$ band on the other hand is the characteristic peak from $\mathrm{sp}^{2}$ hybridization corresponding to the $\mathrm{E}_{2 \mathrm{~g}}$ phonon scattering of carbon atoms. The weak band present around $2640 \mathrm{~cm}^{-1}$ is often associated 
with the 2D band due to the second-order two phonons with opposite momentum in the highest optical branch adjacent to the K point of the Brillouin zone [57]. After hydrothermal reaction, the $\mathrm{D}$ band peak remained unchanged while the G-band peak of their reduced state red-shifted. The increase in the number of $\mathrm{sp}^{2}$ atomic domains and also the successful reduction of GO to a reduced state were evident from the red-shift in the G band [58]. The intercalation induces a red shift of the $G$ band due to the lower Fermi energy level and shifts the band gap due to the doping effect. The slight shift of the $G$ band of the divalent ion intercalated reduced graphene hydrogel in comparison to $\mathrm{rGH}$ also confirms the interaction between graphene and the divalent ion due to charge transfer which has been previously reported [43]. The probing into the order/disorder crystal structures can be observed from the integrated intensity ratio $\left(\mathrm{I}_{\mathrm{D}} / \mathrm{I}_{\mathrm{G}}\right)$ between the $\mathrm{D}$ and $\mathrm{G}$ bands. The $\mathrm{I}_{\mathrm{D}} / \mathrm{I}_{\mathrm{G}}$ of $\mathrm{GO}, \mathrm{rGH}$, rGH-Mg, and rGH-Ca is $0.89,1.00,1.01$, and 1.01, respectively. The increase in the ratio indicated the decrease in the average size of $\mathrm{sp}^{2}$ carbon domains suggesting the easier orientation of the aromatic rings after the removal of the oxygen-containing functional groups. The intercalation of $\mathrm{Mg}^{2+}$ and $\mathrm{Ca}^{2+}$ induced a higher $\mathrm{I}_{\mathrm{D}} / \mathrm{I}_{\mathrm{G}}$ ratio in which it is hypothesized that the divalent ions do not introduce defect from their interaction with the epoxy and carboxyl groups as supported by the FTIR result. The lateral dimension size of the $\mathrm{sp}^{2}$ carbon cluster $\left(L_{\mathrm{a}}\right)$ can be calculated using the following equation $[59,60]$.

$$
L_{\mathrm{a}}(\mathrm{nm})=\left(2.4 \times 10^{-10}\right) \lambda^{4} \frac{1}{I_{D} / I_{G}}
$$

where $\lambda$ is the Raman excitation wavelength of the laser $(532 \mathrm{~nm})$. Based on the $I_{D} / I_{G}$ obtained from Figure 2c, the calculated $L_{a}$ values were 21.60, 19.22, 19.03, and 19.03 for GO, $\mathrm{rGH}, \mathrm{rGH}-\mathrm{Mg}$, and rGH-Ca, respectively. The intercalation of the divalent ions within the hydrogel framework reduced the $L_{\mathrm{a}}$ value, suggesting a decrease in the average in-plane crystallite size of the $\mathrm{sp}^{2}$ carbon.

TGA was further used to probe the thermal stability of the prepared samples. Figure $2 \mathrm{~d}$ displays the TGA thermograms for GO, rGH, rGH-Mg, and rGH-Ca, respectively. GO showed major weight loss ( 30\%) between 100 and $200{ }^{\circ} \mathrm{C}$ which can be attributed to the removal of labile functional groups such as hydroxyl, epoxy and carbonyl which yielded $\mathrm{CO}, \mathrm{CO}_{2}$, and steam [61]. The reduced state samples exhibited a smooth weight loss curve which can be attributed to the removal of most oxygen functional groups via hydrothermal process. Between 100 and $200{ }^{\circ} \mathrm{C}$, the weight loss of the divalent ion intercalated samples was slightly higher than that of $\mathrm{rGH}$, suggesting higher moisture content. It can be inferred that the intercalation of $\mathrm{Mg}^{2+}$ and $\mathrm{Ca}^{2+}$ increase the hygroscopicity of the hydrogels. Closer inspection of the inset in Figure $2 \mathrm{~d}$ shows that the rGH-Mg and rGH-Ca exhibited slight improvement in their thermal stability between $200-400{ }^{\circ} \mathrm{C}$ with a lower mass loss reported which can be attributed to the intercalation effect. However, the weight loss of the hydrogel samples remained basically similar beyond $400{ }^{\circ} \mathrm{C}$.

XPS characterization was further carried out to investigate the elemental composition and also to confirm the successful intercalation of the $\mathrm{Mg}^{2+}$ and $\mathrm{Ca}^{2+}$ within the reduced graphene framework. The quantified atomic concentration of the functional groups is shown in Table 3. Figure 3f depicts the XPS wide spectra of rGH, rGH-Mg, and rGH-Ca. The typical $\mathrm{C}$ 1s and $\mathrm{O}$ 1s peaks can be observed for all the freeze-dried samples with a trace amount of $\mathrm{Mg}$ and $\mathrm{Ca}$ from the intercalation with the graphene sheets. Although the $\mathrm{Ca} 2 \mathrm{p}$ and $\mathrm{Mg} 2 \mathrm{p}$ peaks cannot be observed clearly from the wide peak spectrum, the split peaks indicated otherwise. The atomic percentage of $\mathrm{Ca}$ is greater than $\mathrm{Mg}$ by one-fold which substantiate the notion that $\mathrm{Mg}^{2+}$ is difficult to chelate with the oxygenated groups of the graphene sheets. The low content of the divalent ion could be the reason for their weak signal strength. The deconvoluted high-resolution $\mathrm{C} 1 \mathrm{~s}$ region of the samples was shown in Figure 3a-c, possessing peak binding energies at around 284.6, 285.4, 286.3, 287.1, 287.9, 289.1 and $290.3 \mathrm{eV}$ assigned to $\mathrm{C}=\mathrm{C}, \mathrm{C}-\mathrm{C}, \mathrm{C}-\mathrm{O}, \mathrm{C}=\mathrm{O}, \mathrm{O}-\mathrm{C}-\mathrm{O}, \mathrm{C}(\mathrm{O}) \mathrm{OH}$, and $\pi-\pi^{*}$, respectively. It can be seen that the atomic percentage of alkoxy and epoxy groups significantly decreased which further supports the notion that intercalation occurs via 
ring-opening epoxide by the divalent ions and also via the alkoxy groups. The findings corroborated the result obtained via FTIR. The increase in the Csp ${ }^{2}$ atomic composition percentage also suggests that the divalent ion assisted in the rearrangement of the $C=C$ aromatic structure. Figure $3 \mathrm{~d}$ depicts the fitted $\mathrm{Mg} 2 \mathrm{p}$ core-level spectra deconvoluted to $\mathrm{Mg} 2 \mathrm{p}_{1 / 2}$ and $\mathrm{Mg} 2 \mathrm{p}_{3 / 2}$. The binding energy at $51.4 \mathrm{eV}$ and $48.6 \mathrm{eV}$ correspond to the $\mathrm{Mg}^{2+}$ state and $\mathrm{Mg}^{0}$, respectively. As for the $\mathrm{Ca} 2 \mathrm{p}$ spectra in Figure $3 \mathrm{e}$, the deconvolution at 347.9 and $351.4 \mathrm{eV}$ are attributed to the $\mathrm{Ca} 2 \mathrm{p}_{3 / 2}$ and $\mathrm{Ca} 2 \mathrm{p}_{1 / 2}$. The split of $3.5 \mathrm{eV}$ between the two peaks is evident for the presence of $\mathrm{Ca}^{2+}$ coordination within the graphene framework [43].

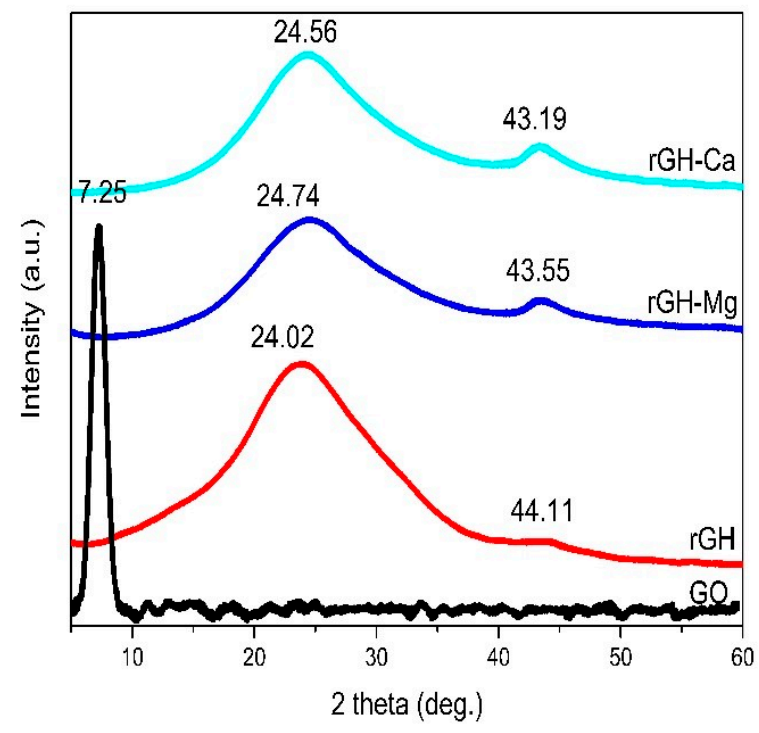

(a)

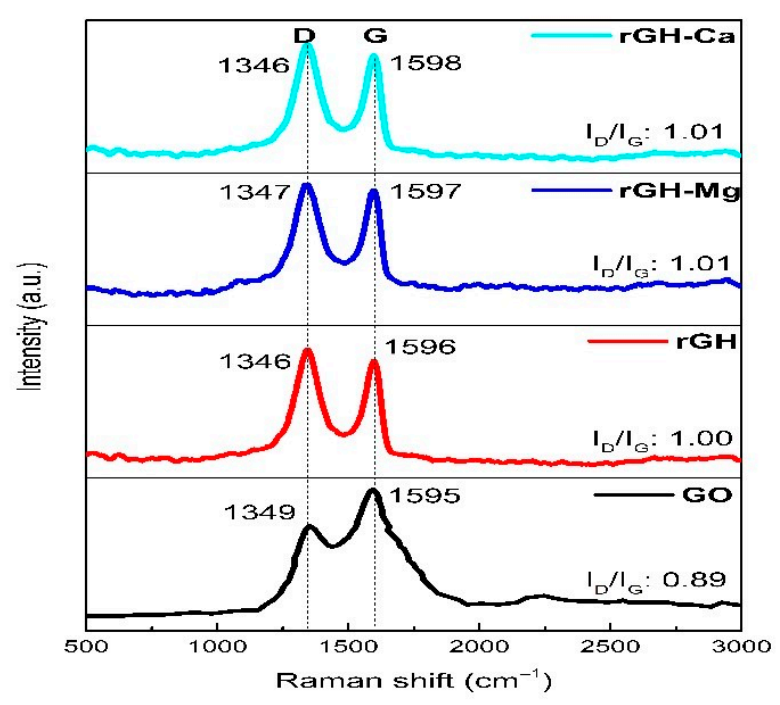

(c)

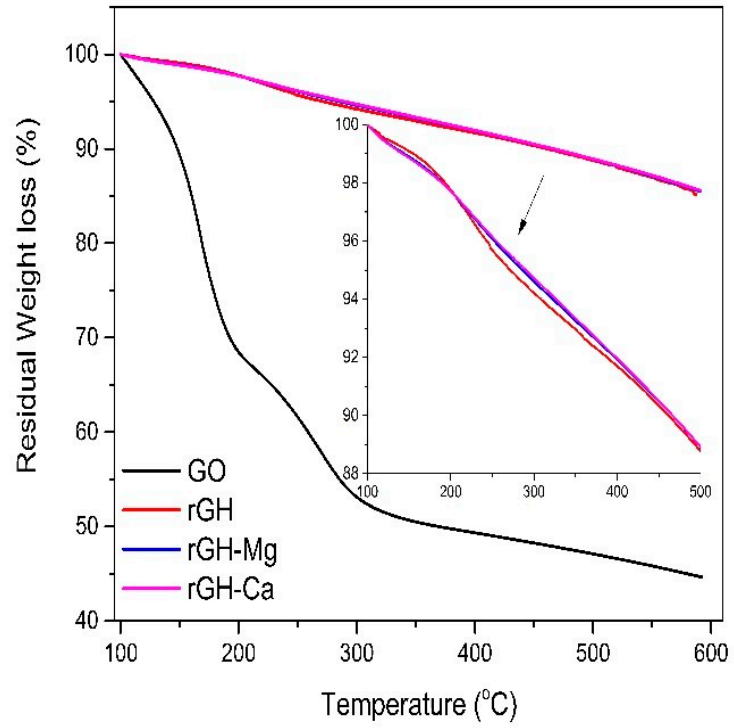

(b)

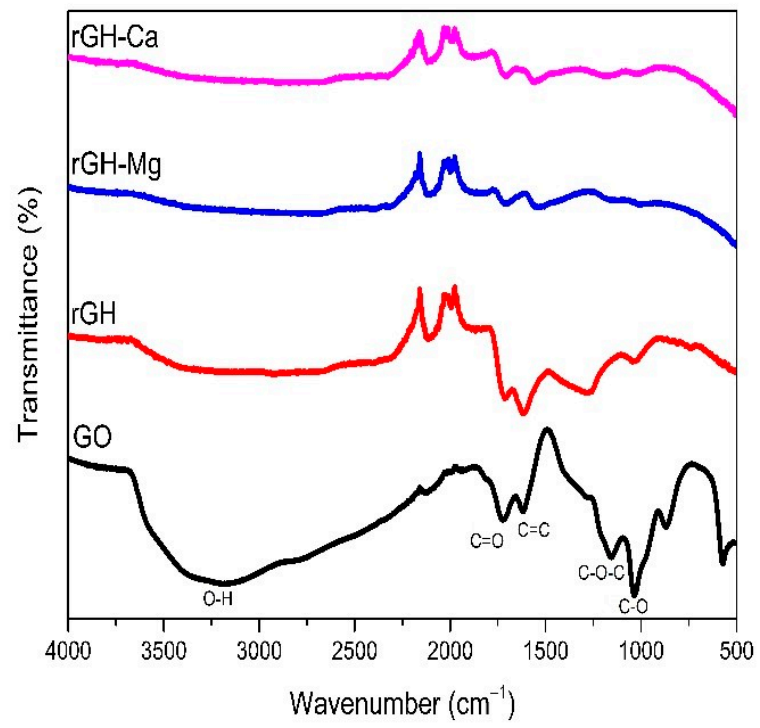

(d)

Figure 2. (a) X-ray diffraction (XRD) pattern, (b) ATR-FTIR spectra, (c) Raman spectra (d) Thermogravimetric analysis (TGA) thermogram of GO, rGH, rGH-Mg, and rGH-Ca. 
Table 3. Elemental composition, and C 1s binding energy obtained from X-ray photoelectron spectroscopy (XPS).

\begin{tabular}{|c|c|c|c|c|c|c|c|c|c|c|c|}
\hline \multirow{2}{*}{ Sample } & \multicolumn{4}{|c|}{ Elemental Composition (\%) } & \multicolumn{7}{|c|}{ C1s Deconvolution (\%) } \\
\hline & $\mathrm{C}$ & $\mathbf{O}$ & $\mathrm{Mg}$ & $\mathrm{Ca}$ & $\mathrm{Csp}^{2}$ & $\mathrm{Csp}^{3}$ & $\mathrm{C}-\mathrm{O}$ & $\mathrm{C}=\mathrm{O}$ & $\mathrm{O}-\mathrm{C}-\mathrm{O}$ & $\mathrm{C}(\mathrm{O}) \mathrm{OH}$ & $\pi-\pi^{*}$ \\
\hline rGH & 67.92 & 32.08 & 0.00 & 0.00 & 69.50 & 9.10 & 13.18 & 2.80 & 3.04 & 0.60 & 1.78 \\
\hline rGH-Mg & 76.65 & 22.46 & 0.89 & 0.00 & 71.72 & 15.77 & 5.92 & 1.89 & 1.48 & 1.95 & 1.26 \\
\hline $\mathrm{rGH}-\mathrm{Ca}$ & 73.54 & 24.47 & 0.00 & 1.99 & 71.89 & 13.41 & 6.23 & 3.76 & 1.87 & 1.58 & 1.27 \\
\hline
\end{tabular}
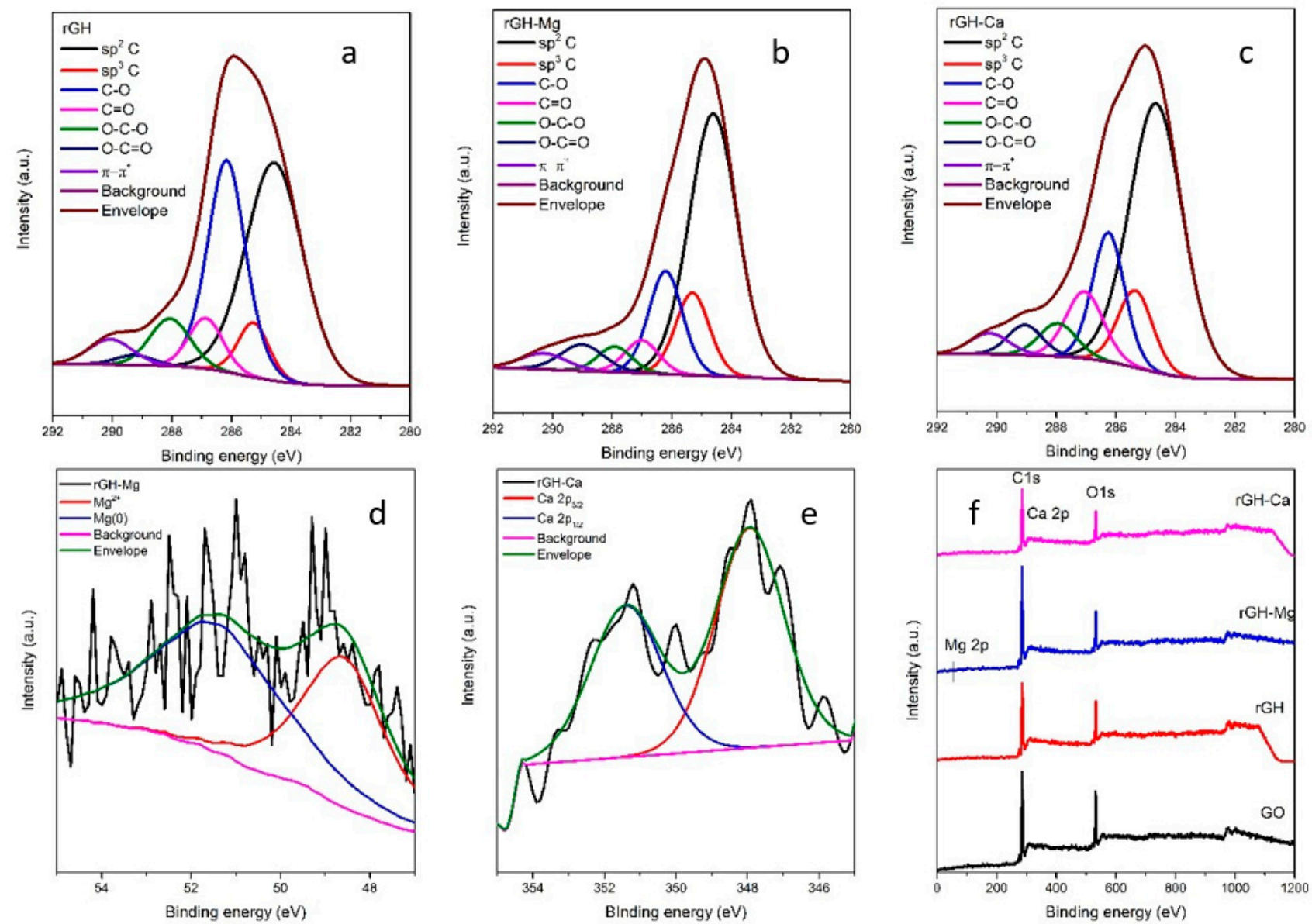

Figure 3. (a-c) C 1s split spectra of rGH, rGH-Mg, and rGH-Ca. (d) Mg 2p split spectra of rGH-Mg. (e) Ca 2p split spectra of rGH-Ca. (f) wide spectra of GO, rGH, rGH-Mg and rGH-Ca.

Figure 4a depicts the nitrogen adsorption-desorption isotherm of the freeze-dried rGH, rGH-Mg, and rGH-Ca which exhibited an $\mathrm{H} 3$ hysteresis loop with the typical type IV isotherm suggesting the presence of mesopores and slit-like pores. It can be seen that the hysteresis loop closes below $0.4 \mathrm{P} / \mathrm{P}_{0}$ which is possible from the smaller neck diameter than the critical size on the reduced graphene hydrogel surface which led to the desorption mechanism occurring from larger pores involving cavitation [62]. Figure $4 \mathrm{~b}$ illustrates the Barrett, Joyner, and Halenda $(\mathrm{BJH})$ pore size distribution which suggests that the pore size distribution of the freeze-dried hydrogels with bimodal pore size distribution around $2 \mathrm{~nm}$ in radius for the mesopores. $\mathrm{BJH}$ method was utilized in the calculation of the pore size distributions and volume from the experimental isotherms using the Kelvin model of pore filling as adapted in previous studies [63-65]. The data was readily obtained from the Nova e software program installed on the workstation. 


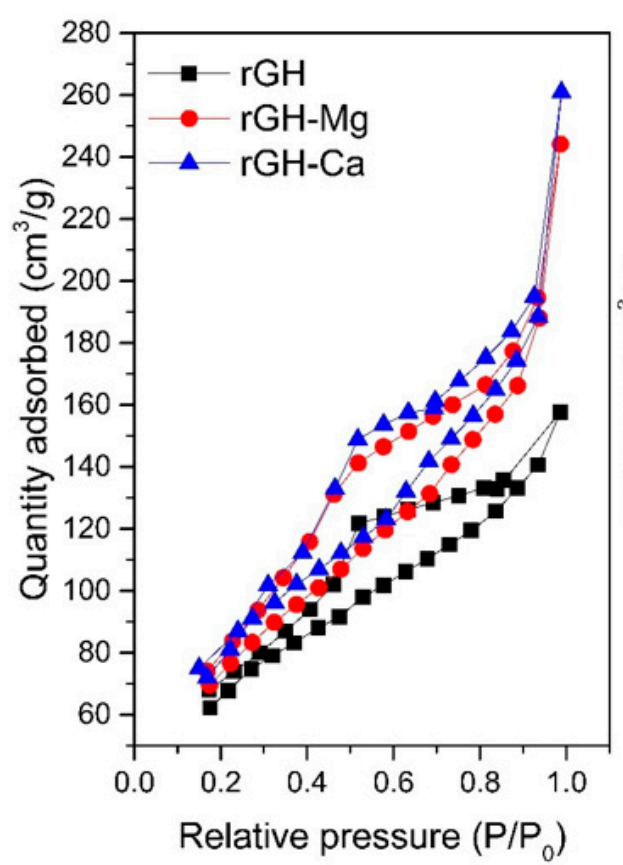

(a)

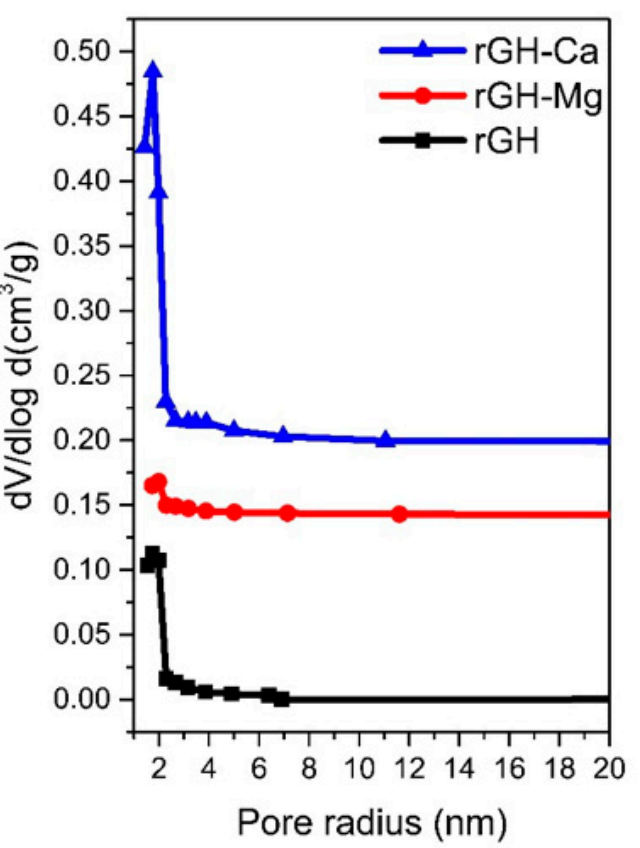

(b)

Figure 4. (a) $\mathrm{N}_{2}$ adsorption-desorption isotherm and (b) Barrete-Joynere-Halenda (BJH) pore size distribution of the freeze-dried rGH, rGH-Mg, and rGH-Ca.

From Table 4, rGH-Ca was found to exhibit the largest surface area at $63.09 \mathrm{~m}^{2} / \mathrm{g}$, followed by rGH-Mg at $50.48 \mathrm{~m}^{2} / \mathrm{g}$ and $\mathrm{rGH}$ at $41.14 \mathrm{~m}^{2} / \mathrm{g}$. The increase in the surface area can be attributed to the successful intercalation of the $\mathrm{Mg}^{2+}$ and $\mathrm{Ca}^{2+}$ that become cross-linkers and also act as spacers between the graphene sheets which create a porous framework. However, the surface area was lower than the theoretical value of exfoliated pristine graphene which is about $2600 \mathrm{~m}^{2} / \mathrm{g}$ which may be attributed to the varying synthesis/drying process. The significant decrease of the hydrogel's surface area could be attributed to the aggregation of the sheets during GO sonication leading to the coalescing of the reduced graphene sheets after hydrothermal treatment as supported by SEM results. Estimating the number of stacking of the graphene sheets can be further realized by applying the scaling law which is described as [66,67]:

$$
\mathrm{N}=2600 / \mathrm{A}
$$

where the $\mathrm{N}$ is the number of graphene sheets per plate, 2600 is the theoretical surface area of graphene $\left(\mathrm{m}^{2} / \mathrm{g}\right)[68]$ and $\mathrm{A}$ is the experimental BET surface area measured $\left(\mathrm{m}^{2} / \mathrm{g}\right)$. It can be seen that the estimated number of graphene sheets present is 63,47 , and 41 for the freeze-dried $\mathrm{rGH}, \mathrm{rGH}-\mathrm{Mg}$, and $\mathrm{rGH}-\mathrm{Ca}$, respectively. It can be observed that the intercalation of the $\mathrm{Mg}^{2+}$ and $\mathrm{Ca}^{2+}$ between the graphene sheets induced higher pore volume which is posited to occur due to the spacing effect elicited from the divalent ions. The higher pore volume obtained for rGH-Ca can be attributed to the larger ionic size of the $\mathrm{Ca}^{2+}$ in comparison to $\mathrm{Mg}^{2+}$. The larger surface area and pore volume after divalent ion intercalation should enhance the diffusion of liquid reactants which are beneficial for the dye adsorption process.

Table 4. Brunauer-Emmett-Teller (BET) surface area and textural properties of freeze-dried hydrogels.

\begin{tabular}{cccc}
\hline Sample & Specific Surface Area $\mathbf{~ m}^{2} / \mathbf{g}$ & Pore Radius Dv(r) & Pore Volume cc/g \\
\hline rGH & 41.135 & 1.741 & 0.145 \\
rGH-Mg & 54.884 & 1.741 & 0.265 \\
rGH-Ca & 63.088 & 1.751 & 0.313 \\
\hline
\end{tabular}




\section{3. $M B$ and $R h B$ Adsorption}

\subsubsection{Effect of Initial Dye Concentration}

From previous studies, adsorption of dye compounds onto the highly porous graphenebased hydrogels can occur via several interactions which may include $\pi-\pi$ interactions, electrostatic interactions, and hydrogen bonding interactions [69,70]. In order to evaluate the in-situ adsorption capacity of rGH, rGH-Mg, and rGH-Ca towards $\mathrm{MB}$ and $\mathrm{RhB}$, the 'wet-hydrogel' sample was used instead of the freeze-dried samples. The wet hydrogel samples were placed in the dye solutions and agitated for $24 \mathrm{~h}$ to achieve the adsorptiondesorption equilibrium. The water content present in the hydrogel matrix not only acts as supporting media and provides transport nanochannels but also promotes hydrogen bonding to induce the adsorption process [71,72]. The findings indicated that the inclusion of a small amount of divalent ion in the hydrogel matrix could bring improvement in their adsorption capacities towards MB and RhB. Based on Figure 5, the effect of initial dye concentration on the adsorption capacity of the hydrogels is shown. It can be seen that the amount of dye adsorbed increased with an increase in the initial concentration. The initial dye concentration provided an important driving force to overcome the mass transfer resistance of the dye and the hydrogel. High dye concentrations increase the gradient between the bulk solution and that of the adsorbent, which enhances the driving forces for the diffusion of dye molecules to the adsorbent surface [73]. Hence, the higher adsorption capacity for dye is expected at a higher initial concentration. Generally, the adsorption capacity for $\mathrm{MB}$ is higher as compared to the $\mathrm{RhB}$ because of the larger size of $\mathrm{RhB}$ [74]. The adsorption capacity of the rGH-Ca showed the highest adsorption capacity at higher initial dye concentration $(100 \mathrm{mg} / \mathrm{L})$ for both $\mathrm{MB}$ and $\mathrm{RhB}$. The adsorption behavior of $\mathrm{RhB}$ corresponds to the surface area of the hydrogel, with rGH-Ca performed the best attributed to their higher surface area in comparison to rGH and rGH-Mg. As for $\mathrm{MB}$ adsorption, $\mathrm{rGH}-\mathrm{Mg}$ and $\mathrm{rGH}-\mathrm{Ca}$ possessed almost similar adsorption capacity at lower $(20$ and $50 \mathrm{mg} / \mathrm{L}$ ) dye concentration. It is posited that at low concentration of dye solution, $\pi-\pi$ interactions plays a determining role in the adsorption process for $\mathrm{rGH}-\mathrm{Mg}$ and $\mathrm{rGH}-\mathrm{Ca}$ which is supported by the almost similar $\mathrm{sp}^{2}$ atomic percentage obtained from the XPS result.

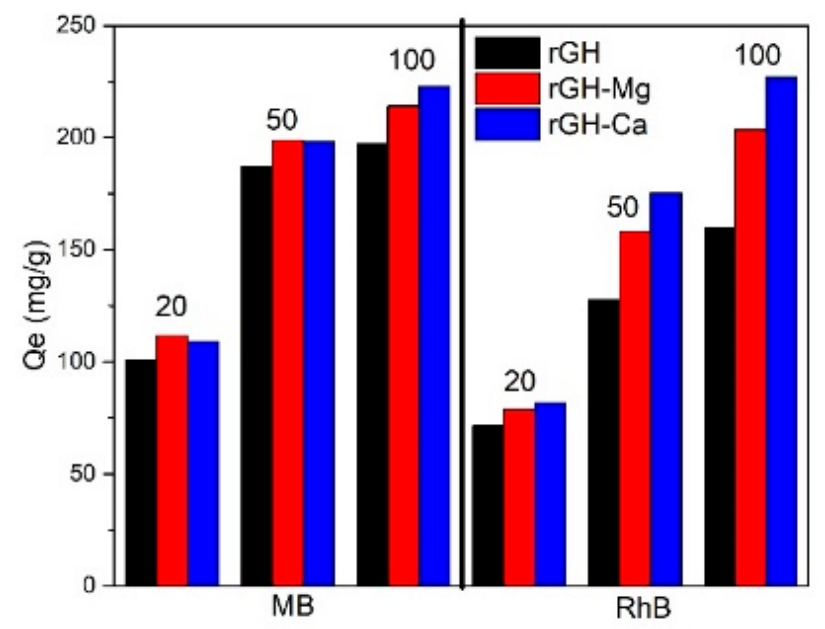

Figure 5. The adsorption capacity of the rGHs using various initial concentration (20,50 and $100 \mathrm{mg} / \mathrm{L}$ ) of methylene blue (MB) and rhodamine B (RhB).

\subsubsection{Adsorption Kinetics}

Kinetic studies were carried out to understand the mechanism involved during the adsorption process. The linear plots of $\ln \left(Q_{e}-Q_{t}\right)$ vs. $t$ and $\ln \left(Q_{e}-Q_{t}\right)$ vs. $t / Q_{t}$ corresponding to the PFO and PSO kinetic models are depicted in Supplementary Figure S4a-d. The linear plot of the Elovich model is obtained from the $Q_{t} \mathrm{vs.} \mathrm{In} t$ as shown in Supplementary Figure S4e,f. The lower regression value for the Elovich model proved that this model is not 
suitable to accurately describe the kinetic process. The kinetic parameters obtained from the models are displayed in Table 5. The kinetic data of MB and RhB adsorption using the hydrogels can be accurately described by the PSO model from the better regression coefficient as compared to the PFO and Elovich model. Moreover, the linear plots of $t / Q_{t}$ versus $t$ indicated good agreement between experimental results and the calculated values. For $\mathrm{MB}$ adsorption, the fastest adsorbing hydrogel is $\mathrm{rGH}$ followed by $\mathrm{rGH}-\mathrm{Mg}$ and $\mathrm{rGH}-\mathrm{Ca}$. While for RhB adsorption, the rate of adsorption showed that rGH-Mg showed the highest rate followed by rGH and $\mathrm{rGH}-\mathrm{Ca}$. Thus, these results revealed that the diffusion of the dye molecules onto the hydrogels is a controlled adsorption, posited to be via chemisorption through binding reaction by sharing/exchange of electrons or covalent forces.

Table 5. Kinetic parameters obtained from the pseudo first-order (PFO), pseudo second-order (PSO) and Elovich kinetic model for the adsorption of MB and RhB.

\begin{tabular}{ccccccccccc}
\hline \multicolumn{1}{c}{ Pseudo-First Order } & \multicolumn{3}{c}{ Pseudo-Second Order } & \multicolumn{3}{c}{ Elovich } \\
\hline Sample & $\boldsymbol{Q}_{\boldsymbol{e}}$ & $\boldsymbol{K}_{\mathbf{1}}$ & $\mathbf{R}^{\mathbf{2}}$ & $\boldsymbol{Q}_{\boldsymbol{e}}$ & $\boldsymbol{K}_{\mathbf{2}}$ & $\mathbf{R}^{\mathbf{2}}$ & $\boldsymbol{\alpha}$ & $\boldsymbol{\beta}$ & $\mathbf{R}^{\mathbf{2}}$ \\
\hline \multicolumn{1}{c}{$\mathrm{MB}$} \\
\hline $\mathrm{rGH}$ & 107.61 & 0.002902 & 0.96962 & 123.92 & 0.000024 & 0.98502 & 1.060 & 0.04440 & 0.93857 \\
$\mathrm{rGH}-\mathrm{Mg}$ & 123.41 & 0.002902 & 0.95907 & 140.85 & 0.000018 & 0.97394 & 1.087 & 0.03985 & 0.91910 \\
rGH-Ca & 118.32 & 0.002695 & 0.93354 & 138.89 & 0.000018 & 0.97647 & 1.054 & 0.04054 & 0.92249 \\
\hline \multicolumn{10}{c}{$\mathrm{RhB}$} \\
\hline rGH & 40.55 & 0.001914 & 0.95924 & 74.68 & 0.0001242 & 0.98612 & 17.846 & 0.12314 & 0.74884 \\
rGH-Mg & 37.71 & 0.001794 & 0.96048 & 74.35 & 0.0001496 & 0.98806 & 31.446 & 0.13240 & 0.73716 \\
rGH-Ca & 40.55 & 0.002096 & 0.96130 & 87.26 & 0.0000981 & 0.98204 & 10.678 & 0.09706 & 0.75825 \\
\hline
\end{tabular}

From Figure 6, the plot of $Q_{t}$ versus $t^{1 / 2}$ confirms the multistage adsorption of (a) MB and (b) RhB molecules with three slopes obtained. The first linear line indicated the transfer of dye molecules to the external surface posited to occur via strong electrostatic interactions. The second linear line corresponds to the slow adsorption step in which the dye molecules entered the internal porous network of the hydrogels via intraparticle diffusion. The final stage is the final equilibrium step, in which the dye molecules moved slowly from the larger pores to the smaller pores, leading to a retarded adsorption rate $[75,76]$.

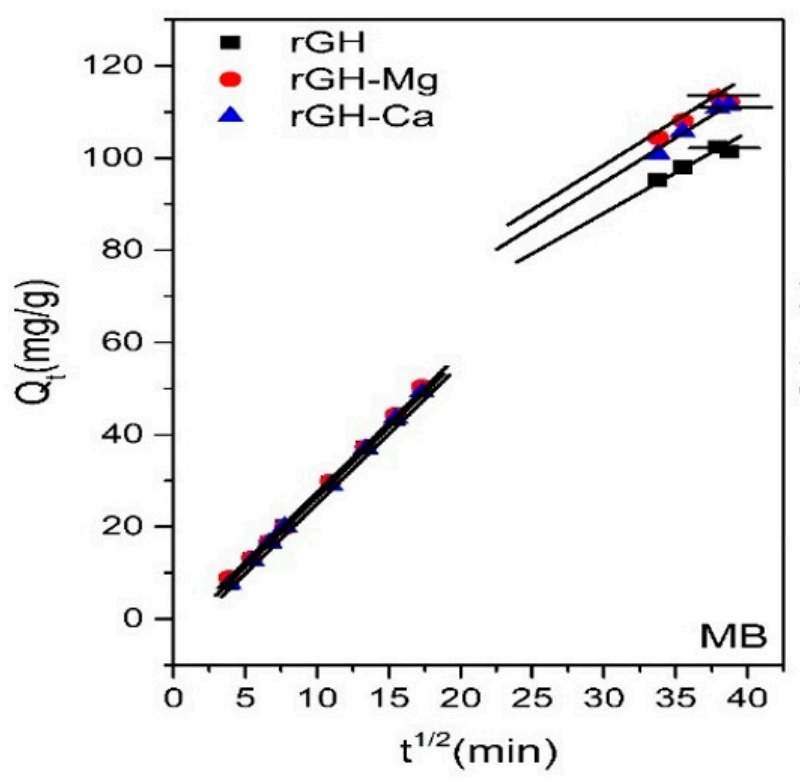

(a)

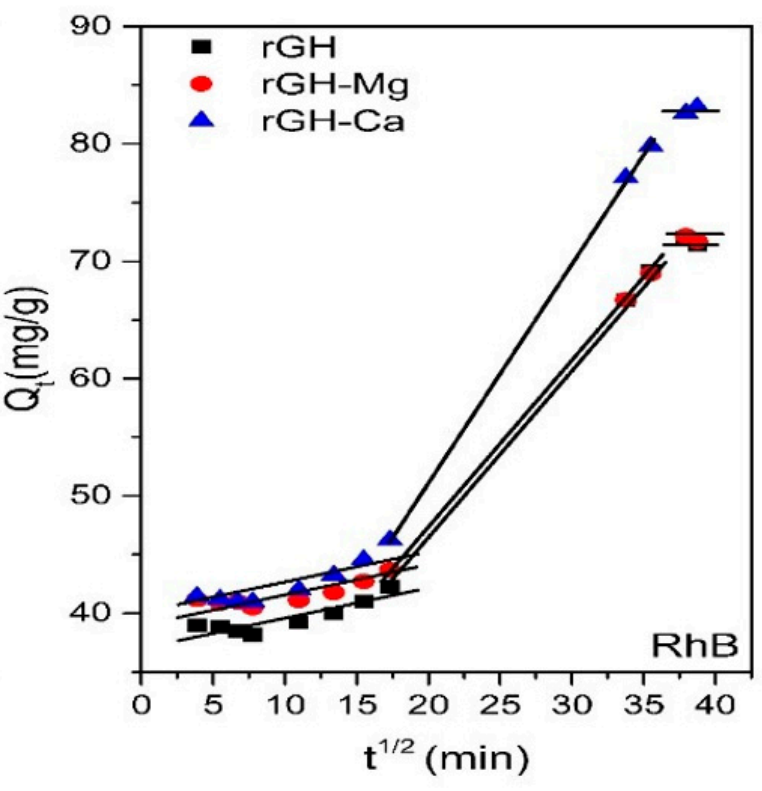

(b)

Figure 6. Intraparticle diffusion (IPD) plot of (a) MB and (b) RhB adsorption onto the hydrogels. 
From Supplementary Table S1, the negative C value obtained for MB absorption can be attributed to the combined effects of film diffusion and surface reaction control which has been previously reported [77]. For MB adsorption, $K_{1}>K_{2}$ indicated a faster diffusion process during the initial stage of adsorption. However, as for RhB adsorption, the value of $K_{1}>K_{2}$, indicating that IPD process was faster than the first step. Hence, it is considered that surface adsorption involving PSO and IPD are involved simultaneously in the adsorption of the dye compounds.

\subsubsection{Adsorption Isotherm}

The study into the adsorption isotherm provided vital insights into the interaction behavior of the adsorbate and adsorbent. It is important to establish the correlation for the equilibrium curve for the optimization of a dye adsorption system. Table 6 summarizes the equilibrium isotherm constant for the adsorption of $\mathrm{MB}$ and $\mathrm{RhB}$ using the hydrogels. For both the adsorption of $\mathrm{MB}$ and $\mathrm{RhB}$, it was found that the experimental data conformed to the Langmuir isotherm model yielding linear correlation coefficients $\left(R^{2}\right)$ closer to unity for $\mathrm{rGH}, \mathrm{rGH}-\mathrm{Mg}$, and rGH-Ca as compared to Freundlich and Temkin isotherm model. Hence, it can be posited that the adsorption sites on the rGHs were occupied by dye molecules in monolayer form having the same adsorption energy. Further, Langmuir isotherm can be used to access the maximum adsorption capacity $\left(Q_{m}\right)$ of the hydrogels towards MB and $\mathrm{RhB}$. Interestingly, the maximum adsorption capacity for $\mathrm{MB}$ followed the following trend: $\mathrm{rGH}(282.49 \mathrm{mg} / \mathrm{g})>$ rGH-Ca $(224.22 \mathrm{mg} / \mathrm{g})>$ rGH-Mg $(243.31 \mathrm{mg} / \mathrm{g})$. From XPS measurement, the presence of a higher percentage of oxygenated functionalities on rGH promote interactions with the MB. It is posited that the surface of $\mathrm{rGH}$ is surrounded by a higher number of functional groups, such as carboxyl, hydroxyl, and epoxy groups as the binding sites which drives the adsorption capacity with the cationic dye, MB. However, the interaction between the divalent ion intercalated $\mathrm{rGH}$ showed higher $\mathrm{K}_{\mathrm{L}}$ values which indicated greater interaction between $\mathrm{rGH}$ and $\mathrm{MB}$ which is important for the post-treatment process. On the other hand, the RhB adsorption followed the following isotherm model in order: Langmuir $>$ Temkin $>$ Freundlich. The maximum adsorption capacity $\left(\mathrm{Q}_{\mathrm{m}}\right)$ for $\mathrm{RhB}$ followed the following trend: $\mathrm{rGH}-\mathrm{Ca}(299.40 \mathrm{mg} / \mathrm{g})>$ rGH-Mg $(260.42 \mathrm{mg} / \mathrm{g})>\mathrm{rGH}(192.31 \mathrm{mg} / \mathrm{g})$ which showed that the intercalated divalent ion improved the maximum adsorption capacity by almost $35 \%$ and $57 \%$ for $\mathrm{Mg}^{2+}$ and $\mathrm{Ca}^{2+}$, respectively. The affinity between adsorbate and absorbent was accessed using the dimensionless separation factor, $R_{L}$ which can be expressed as:

$$
R_{L}=\frac{1}{1+K_{L} C_{0}}
$$

where $K_{L}$ is the calculated Langmuir constant and $C_{0}$ is the initial concentration of the dye solution. Often, the $R_{L}\left(0<R_{L}<1\right)$ indicate a favorable isotherm, while $\left(R_{L}>1\right)$ is unfavorable and $\left(R_{L}=1\right)$ is linear. The separation factors calculated for all the hydrogel samples indicated that the adsorption of both the cationic dyes is favorable.

In terms of the adsorption performance of the divalent ion intercalated $\mathrm{rGH}$ with previously reported adsorbent for $\mathrm{MB}$ and $\mathrm{RhB}$, the intercalated divalent rGHs were comparable to that of previously reported adsorbents. Table 7 represents some adsorption capacity of some hydrogel-based adsorbents. The differences in their adsorption capacity can be attributed to various factors including the functionalities, textural properties, and experimental conditions. The results showed that the adsorption capacity of divalent ion intercalated rGH prepared using the facile hydrothermal method is comparable in terms of their adsorption capacity. It is posited that the adsorption of various noxious pollutants, such as heavy metals, emerging contaminants, etc., is also possible using the divalent ion intercalated rGHs attributed to their inherent unique porous structure. 
Table 6. Langmuir, Freundlich, and Temkin equilibrium isotherm constant for the adsorption of MB and RhB.

\begin{tabular}{|c|c|c|c|c|c|c|c|c|c|}
\hline & \multicolumn{3}{|c|}{ Langmuir Model } & \multicolumn{3}{|c|}{ Freundlich Model } & \multicolumn{3}{|c|}{ Temkin Model } \\
\hline Sample & $Q_{m}$ & $K_{L}$ & $\mathbf{R}^{2}$ & $K_{F}$ & $\mathbf{n}$ & $\mathrm{R}^{2}$ & $K_{T}$ & B & $\mathrm{R}^{2}$ \\
\hline \multicolumn{10}{|c|}{ MB } \\
\hline rGH & 282.49 & 0.09056 & 0.98769 & 78.40 & 4.937 & 0.45218 & 0.3208 & 132.33 & 0.66571 \\
\hline rGH-Mg & 224.22 & 0.29419 & 0.99999 & 87.62 & 4.4905 & 0.89475 & 0.5799 & 111.74 & 0.55911 \\
\hline $\mathrm{rGH}-\mathrm{Ca}$ & 243.31 & 0.15498 & 0.99968 & 69.66 & 3.4775 & 0.88091 & 0.3039 & 140.57 & 0.66571 \\
\hline \multicolumn{10}{|c|}{$\mathrm{RhB}$} \\
\hline rGH & 192.31 & 0.006157 & 0.99968 & 31.05 & 2.602 & 0.95183 & 0.6045 & 41.72 & 0.99476 \\
\hline rGH-Mg & 260.42 & 0.049016 & 0.99999 & 29.88 & 2.177 & 0.95183 & 0.3370 & 69.60 & 0.99187 \\
\hline $\mathrm{rGH}-\mathrm{Ca}$ & 299.40 & 0.045294 & 0.99906 & 29.62 & 2.026 & 0.94789 & 0.3681 & 73.00 & 0.99903 \\
\hline
\end{tabular}

Table 7. Adsorption capacities of $\mathrm{MB}$ and $\mathrm{RhB}$ onto various hydrogel-based adsorbents.

\begin{tabular}{|c|c|c|c|c|c|}
\hline Adsorbate & Adsorbent & Kinetic Model & Adsorption Isotherm & $Q_{e}(m g / g)$ & Reference \\
\hline \multirow{12}{*}{ MB } & rGH & $\mathrm{PSO} / \mathrm{IPD}$ & Langmuir & 123.92 & This work \\
\hline & rGH-Mg & $\mathrm{PSO} / \mathrm{IPD}$ & Langmuir & 140.85 & This work \\
\hline & rGH-Ca & PSO/IPD & Langmuir & 138.89 & This work \\
\hline & Silver/tetraphenylporphyrin/rGH & PSO & - & 130.37 & [78] \\
\hline & $\mathrm{N}, \mathrm{N}$-dimethylacrylamide/2- & & & & \\
\hline & $\begin{array}{l}\text { hydroxyethyl } \\
\text { methacrylate }\end{array}$ & PSO & Langmuir & 80.27 & [79] \\
\hline & Chitosan-carbon nanotubes & $\mathrm{PSO}$ & - & 21.74 & [80] \\
\hline & P-N-graphene oxide & $\mathrm{PSO}$ & - & 12.71 & [81] \\
\hline & $\begin{array}{l}\text { Polyvinyl alcohol/carboxylmetyl } \\
\text { cellulose/ graphene oxide / bentonite }\end{array}$ & PSO & Langmuir & 157.50 & {$[82]$} \\
\hline & Tannic acid $/ \mathrm{rGH}$ & PSO & Langmuir & 348.40 & [27] \\
\hline & $\begin{array}{l}\text { Polyacrylamide-agar/Clay@reduced } \\
\text { graphene oxide }\end{array}$ & $\mathrm{PSO}$ & Langmuir & 189.00 & [83] \\
\hline & $\begin{array}{c}\text { Graphene oxide-cellulose } \\
\text { nanowhiskers }\end{array}$ & PSO & - & 122.5 & {$[84]$} \\
\hline \multirow{8}{*}{$\operatorname{RhB}$} & rGH & PSO/IPD & Langmuir & 74.68 & This work \\
\hline & rGH-Mg & $\mathrm{PSO} / \mathrm{IPD}$ & Langmuir & 74.35 & This work \\
\hline & rGH-Ca & PSO/IPD & Langmuir & 87.26 & This work \\
\hline & $\begin{array}{l}\text { Graphene oxide-cellulose } \\
\text { nanowhiskers }\end{array}$ & PSO & - & 62.00 & [84] \\
\hline & Reduced graphene oxide $/ \mathrm{Nd}_{2} \mathrm{O}_{3}$ & PSO & - & 244.50 & [85] \\
\hline & $\begin{array}{c}\text { Polyacrylamide-agar/Clay@ reduced } \\
\text { graphene oxide }\end{array}$ & $\mathrm{PSO}$ & Langmuir & 186.40 & [83] \\
\hline & P-N- graphene oxide & $\mathrm{PSO}$ & - & 11.91 & [81] \\
\hline & Chitosan-carbon nanotubes & PSO & - & 9.66 & {$[80]$} \\
\hline
\end{tabular}

\subsubsection{Adsorption Mechanism}

In order to elucidate the active sites and interaction between the as-prepared reduced graphene hydrogels and the dyes, the hydrogels collected after adsorption for $24 \mathrm{~h}$ were freeze-dried and subjected to FTIR analysis. The interaction of the cationic dyes might occur either via physical or chemical bonding such as $\pi-\pi$ interactions, hydrogen bonding, and/or via electrostatic interactions. The FTIR before and after the adsorption of MB and RhB was shown in Figure 7a,b, respectively. For pure MB, peaks appearing at 3430 and $1181 \mathrm{~cm}^{-1}$ is attributed to the $\mathrm{O}-\mathrm{H}$ and $\mathrm{C}=\mathrm{C}$ skeleton of the aromatic rings, respectively. The spectra ranging from 1600 to 1341 are assigned to the aromatic ring structures of MB [86]. The interaction with $\mathrm{MB}$ shifted the $\mathrm{C}=\mathrm{O}$ bond $\left(\sim 1714 \mathrm{~cm}^{-1}\right)$ and also almost completely removed the $\mathrm{C}-\mathrm{OH}\left(\sim 1250 \mathrm{~cm}^{-1}\right)$ and $\mathrm{C}-\mathrm{O}-\mathrm{C}\left(1040 \mathrm{~cm}^{-1}\right)$ suggesting strong electrostatic 
interactions. On the other hand, the adsorption of the RhB showed new adsorption peaks around $\sim 800 \mathrm{~cm}^{-1}$ and $\sim 1390 \mathrm{~cm}^{-1}$ indicating chemical interactions with the rGHs.

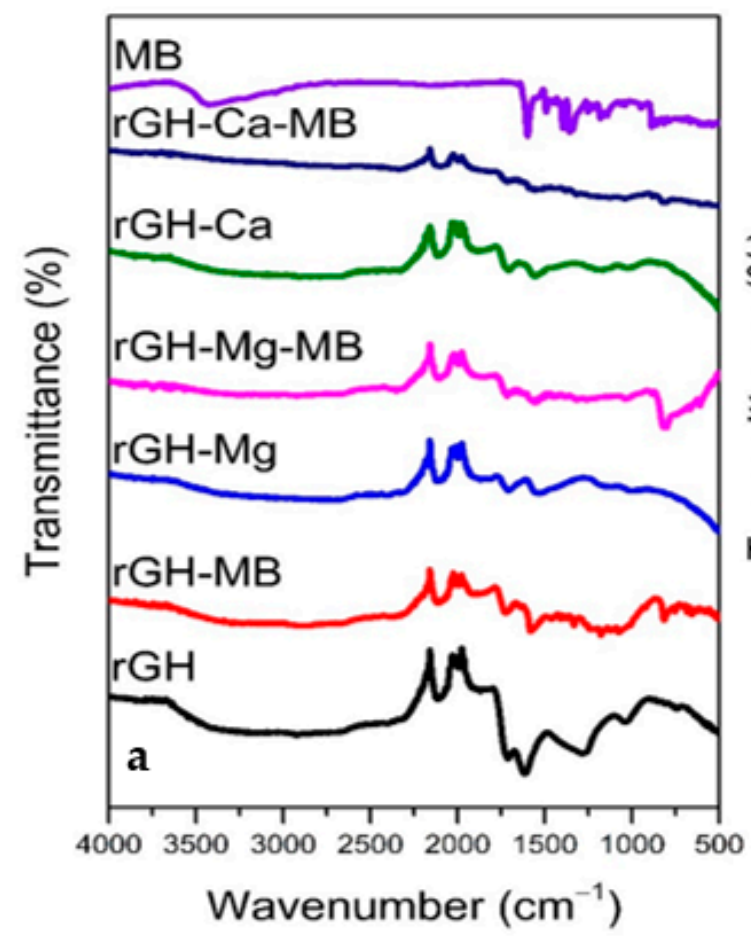

(a)

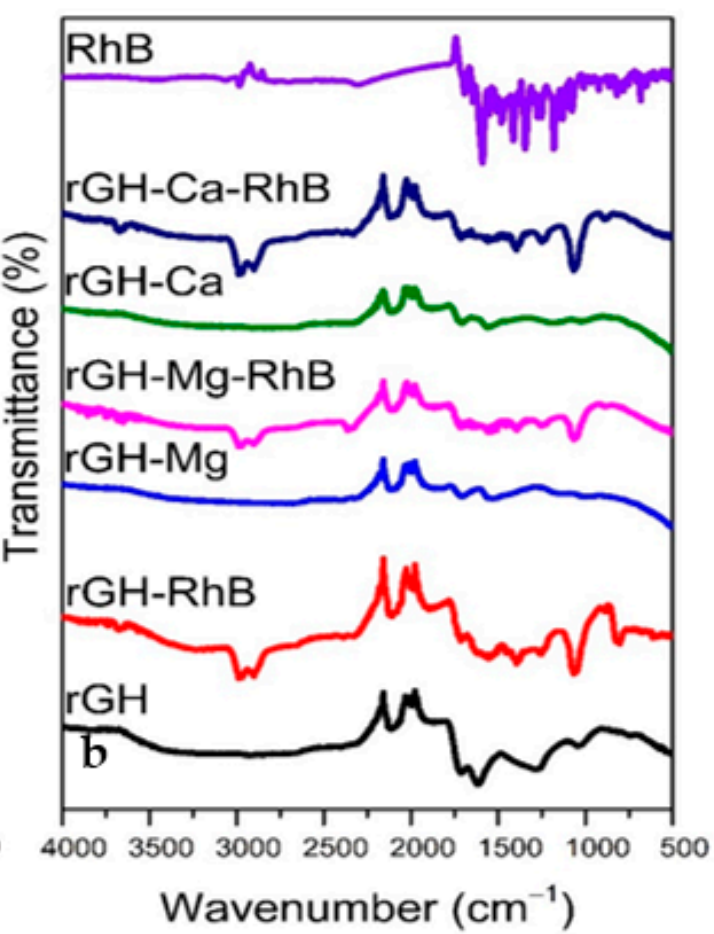

(b)

Figure 7. FTIR of freeze-dried rGHs before and after adsorption with (a) MB and (b) RhB.

Pure RhB showed typical bands at 2984, 1590, and $1345 \mathrm{~cm}^{-1}$ [87]. The peaks appearing around 2987 and $2900 \mathrm{~cm}^{-1}$ corresponded to the C-H stretching vibration of the $\mathrm{RhB}$ adsorbed on the surface of the hydrogels. The slight introduction of the peak around $\sim 3300 \mathrm{~cm}^{-1}$ may be attributed to the hydrogen bonding that occurs with the RhB. In addition, the increase in the intensity of the $1060 \mathrm{~cm}^{-1}$ corresponded to the $\mathrm{C}-\mathrm{O}$, indicating that the interaction with $\mathrm{RhB}$ also is driven by electrostatic interaction.

\subsubsection{Simultaneous Adsorption of $\mathrm{MB}$ and $\mathrm{RhB}$}

From the kinetic studies, chemisorption has been posited to be one of the main driving forces that govern the adsorption mechanism of the divalent ion intercalated rGHs; possibly due to the electrostatic interactions. In order to access the adsorption affinity towards the dye molecules (MB and $\mathrm{RhB}$ ), simultaneous adsorption studies were conducted by placing the as-prepared hydrogel in aqueous solution containing an equal concentration of both dye molecules. From visual observation, the rGHs showed greater affinity towards cationic MB dye as compared to the RhB dye as depicted in Supplementary Figure S5 from the clear change in color (from bluish to pinkish) before and after adsorption. The possible explanation can be attributed to the electrostatic interaction due to the positive charged sulfur and nitrogen in MB structure, hence driving the adsorption process further in addition to the porous structure framework. In addition, the IPD parameters of MB adsorption further corroborated the findings, with MB having higher $K_{1}$ values. Similar adsorption affinity behavior has also been previously reported elsewhere $[88,89]$.

\subsubsection{Recyclability and Reusability}

Considering the potential practical application and to reduce material cost, the divalent ion intercalated hydrogels should possess excellent recyclability and reusability. The cycling 
adsorption experiments were performed to access the regeneration efficiency of the asprepared hydrogels. The results were depicted in Figure 8a,b respectively After each cycle of adsorption, the hydrogels were dialyzed in dilute $\mathrm{HCl}$ for $6 \mathrm{~h}$ and washed with $\mathrm{H}_{2} \mathrm{O}$ before the regenerated hydrogels were subjected to the next adsorption cycle. It can be seen that the regeneration efficiency decreased each cycle which is due to loss of small graphene fragments during the adsorption/desorption under agitation; hence leading to reduced surface area for interactions. After three cycles of adsorption-desorption, the divalent ion intercalated hydrogels maintained above $95 \%$ of its initial capacity demonstrating good adsorption recyclability for both $\mathrm{MB}$ and $\mathrm{RhB}$ which is an added value for large scale applications. In comparison, the adsorption capacity obtained for $\mathrm{rGH}$ is only about 89.3 and $88.5 \%$ for $\mathrm{MB}$ and $\mathrm{RhB}$, respectively. Therefore, the divalent ion intercalated hydrogels can be used as an efficient cationic dye adsorbent.
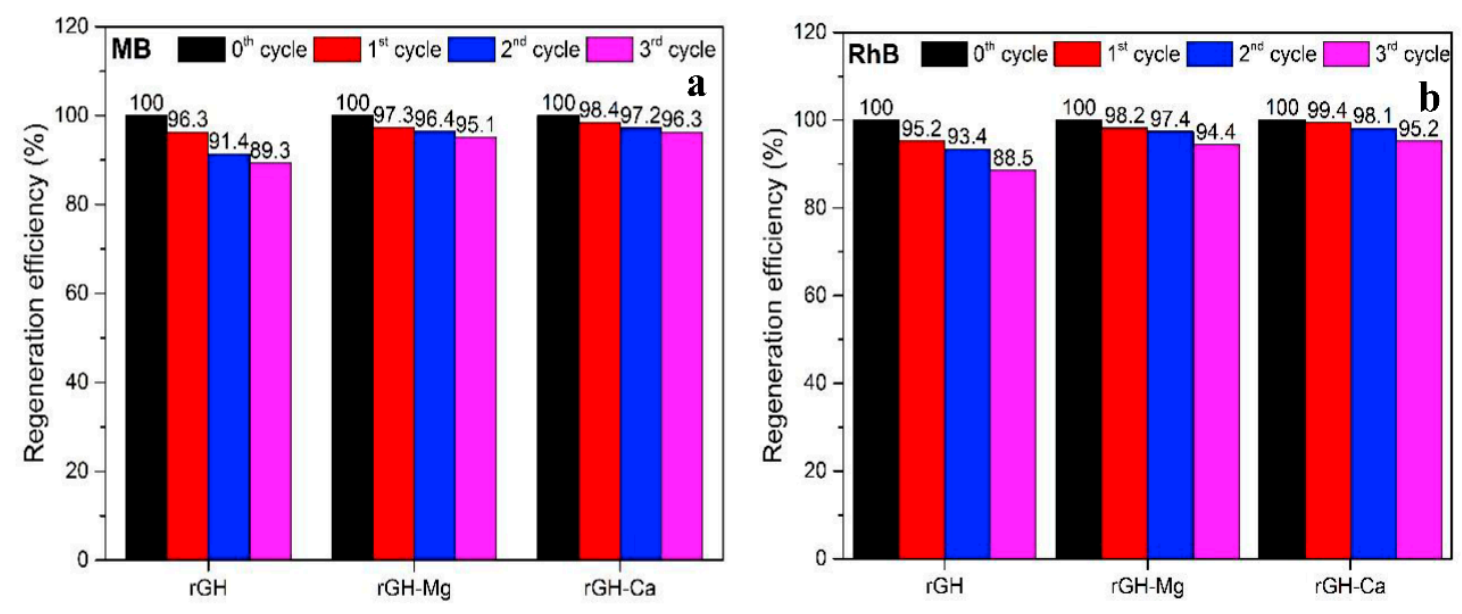

Figure 8. Regeneration efficiency after adsorption of (a) MB and (b) RhB after 3 cycles.

\section{Conclusions}

In the present work, divalent ion intercalated reduced graphene hydrogel was successfully prepared via hydrothermal treatment. The intercalation of $\mathrm{Mg}^{2+}$ and $\mathrm{Ca}^{2+} \mathrm{rGH}$ occurred via the alkoxyl and epoxy functional groups showed improved performance towards the adsorption of cationic dyes, $\mathrm{MB}$, and $\mathrm{RhB}$ with a higher affinity towards $\mathrm{MB}$. The improvement in their adsorption capacity can be attributed to the increase in their physical attributes such as surface area and pore volume. The adsorption kinetics and the equilibrium adsorption isotherm conformed to a pseudo-second-order (PSO) alongside intraparticle diffusion (IPD) kinetic models and Langmuir isotherm respectively. The interaction between the divalent ion intercalated $\mathrm{rGH}$ showed higher $\mathrm{K}_{\mathrm{L}}$ values which indicated greater interaction with the dye molecules which is important for the post-treatment process. The regeneration process indicated the good recovery and efficiency after three cycles which is an important factor to address the inherent problem with powder-based adsorbents. Thus, the present investigation provided further insight into the application of divalent ion intercalated graphene-based hydrogels as dye adsorbents which are efficient, economical, and environmentally friendly in the treatment of dye wastewater.

Supplementary Materials: The following are available online at https:/ / www.mdpi.com/2227-971 7/9/1/169/s1, Figure S1: The absorption spectrum and linear concentration curve of (a) RhB and (b) MB under varying concentration, Figure S2: UV-vis spectrum of GO suspension in the presence of $\mathrm{MgCl}_{2}$ and $\mathrm{CaCl}_{2}$, Figure S3: Digital image of freeze-dried (a) $\mathrm{rGH}$, (b) $\mathrm{rGH}-\mathrm{Mg}$, and (c) rGH-Ca, Figure S4: Pseudo first order $(a, b)$, Pseudo-second order $(c, d)$ and Elovich kinetic model $(e, f)$ of $\mathrm{MB}$ and RhB adsorption on the hydrogels, Table S1: The parameters of the intraparticle diffusion model by the hydrogels. Figure S5: Digital image of the dye solution before (a) and after for (b) rGH, (c) $\mathrm{rGH}-\mathrm{Mg}$, and (d) $\mathrm{rGH}-\mathrm{Ca}$ in the simultaneous adsorption of $\mathrm{MB}$ and $\mathrm{RhB}$. 
Author Contributions: Conceptualization, A.L.T.Z. and Y.A.; methodology, Y.A.; validation, A.L.T.Z.; formal analysis, A.L.T.Z. and S.B.; investigation, A.L.T.Z. and S.B.; resources, T.O. and Y.A.; data curation, Y.A.; writing-original draft preparation, A.L.T.Z.; writing-review and editing, Y.A.; visualization, A.L.T.Z.; supervision, T.O. and Y.A.; project administration, Y.A. All authors have read and agreed to the published version of the manuscript.

Funding: This research received no external funding.

Institutional Review Board Statement: Not applicable.

Informed Consent Statement: Not applicable.

Data Availability Statement: Data is contained within the article and Supplementary Materials.

Acknowledgments: A.L.T.Z. would like to acknowledge Japan's Ministry of Education, Culture, Sports, Science and Technology (MEXT) for the scholarship awarded for his Ph.D. studies. The authors are grateful to Assoc. Toshiki Tsubota for his permission to utilize the Raman spectrometer in his laboratory.

Conflicts of Interest: The authors declare no conflict of interest.

\section{References}

1. Berradi, M.; Hsissou, R.; Khudhair, M.; Assouag, M.; Cherkaoui, O.; El Bachiri, A.; El Harfi, A. Textile finishing dyes and their impact on aquatic environs. Heliyon 2019, 5, e02711. [CrossRef]

2. Yaseen, D.A.; Scholz, M. Textile dye wastewater characteristics and constituents of synthetic effluents: A critical review. Int. J. Environ. Sci. Technol. 2019, 16, 1193-1226. [CrossRef]

3. Lellis, B.; Fávaro-Polonio, C.Z.; Pamphile, J.A.; Polonio, J.C. Effects of textile dyes on health and the environment and bioremediation potential of living organisms. Biotechnol. Res. Innov. 2019, 3, 275-290. [CrossRef]

4. Wang, Z.; Xue, M.; Huang, K.; Liu, Z. Textile Dyeing Wastewater Treatment. In Advances in Treating Textile Effluent; InTech Open: London, UK, 2011.

5. Nageeb, M. Adsorption Technique for the Removal of Organic Pollutants from Water and Wastewater. In Organic PollutantsMonitoring, Risk and Treatment; InTech Open: London, UK, 2013.

6. Crini, G.; Lichtfouse, E.; Wilson, L.D.; Morin-Crini, N. Conventional and non-conventional adsorbents for wastewater treatment. Environ. Chem. Lett. 2019, 17, 195-213. [CrossRef]

7. Gupta, V.K. Suhas Application of low-cost adsorbents for dye removal-A review. J. Environ. Manag. 2009, 90, $2313-2342$. [CrossRef] [PubMed]

8. De Gisi, S.; Lofrano, G.; Grassi, M.; Notarnicola, M. Characteristics and adsorption capacities of low-cost sorbents for wastewater treatment: A review. Sustain. Mater. Technol. 2016, 9, 10-40. [CrossRef]

9. Bano, Z.; Mazari, S.A.; Saeed, R.M.Y.; Majeed, M.A.; Xia, M.; Memon, A.Q.; Abro, R.; Wang, F. Water decontamination by 3D graphene based materials: A review. J. Water Process Eng. 2020, 36, 101404. [CrossRef]

10. Kyzas, G.Z.; Deliyanni, E.A.; Bikiaris, D.N.; Mitropoulos, A.C. Graphene composites as dye adsorbents: Review. Chem. Eng. Res. Des. 2018, 129, 75-88. [CrossRef]

11. Khurana, I.; Saxena, A.; Bharti; Khurana, J.M.; Rai, P.K. Removal of Dyes Using Graphene-Based Composites: A Review. Water Air Soil Pollut. 2017, 228, 180. [CrossRef]

12. Hiew, B.Y.Z.; Lee, L.Y.; Lee, X.J.; Thangalazhy-Gopakumar, S.; Gan, S.; Lim, S.S.; Pan, G.-T.; Yang, T.C.-K.; Chiu, W.S.; Khiew, P.S. Review on synthesis of 3D graphene-based configurations and their adsorption performance for hazardous water pollutants. Process Saf. Environ. Prot. 2018, 116, 262-286. [CrossRef]

13. Allen, M. Honeycomb Carbon-A Study of Graphene. Ph.D. Thesis, University of California, Los Angeles, CA, USA, 2009.

14. Cheng, Y.; Zhou, S.; Hu, P.; Zhao, G.; Li, Y.; Zhang, X.; Han, W. Enhanced mechanical, thermal, and electric properties of graphene aerogels via supercritical ethanol drying and high-temperature thermal reduction. Sci. Rep. 2017, 7, 1-11. [CrossRef]

15. Sur, U.K. Graphene: A Rising Star on the Horizon of Materials Science. Int. J. Electrochem. 2012, 2012, 1-12. [CrossRef]

16. Lee, X.J.; Hiew, B.Y.Z.; Lai, K.C.; Lee, L.Y.; Gan, S.; Thangalazhy-Gopakumar, S.; Rigby, S. Review on graphene and its derivatives: Synthesis methods and potential industrial implementation. J. Taiwan Inst. Chem. Eng. 2019, 98, 163-180. [CrossRef]

17. Meyer, J.C.; Geim, A.K.; Katsnelson, M.I.; Novoselov, K.S.; Booth, T.J.; Roth, S. The structure of suspended graphene sheets. Nature 2007, 446, 60-63. [CrossRef] [PubMed]

18. Zhang, F.; Li, Y.-H.; Li, J.-Y.; Tang, Z.-R.; Xu, Y.-J. 3D graphene-based gel photocatalysts for environmental pollutants degradation. Environ. Pollut. 2019, 253, 365-376. [CrossRef] [PubMed]

19. Hu, K.; Xie, X.; Cerruti, M.; Szkopek, T. Controlling the shell formation in hydrothermally reduced graphene hydrogel. Langmuir 2015, 31, 5545-5549. [CrossRef] [PubMed]

20. Hu, K.; Xie, X.; Szkopek, T.; Cerruti, M. Understanding hydrothermally reduced graphene oxide hydrogels: From reaction products to hydrogel properties. Chem. Mater. 2016, 28, 1756-1768. [CrossRef] 
21. Liu, F.; Chung, S.; Oh, G.; Seo, T.S. Three-Dimensional Graphene Oxide Nanostructure for Fast and Efficient Water-Soluble Dye Removal. ACS Appl. Mater. Interfaces 2012, 4, 922-927. [CrossRef] [PubMed]

22. Lai, K.C.; Lee, L.Y.; Hiew, B.Y.Z.; Thangalazhy-Gopakumar, S.; Gan, S. Environmental application of three-dimensional graphene materials as adsorbents for dyes and heavy metals: Review on ice-templating method and adsorption mechanisms. J. Environ. Sci. 2019, 79, 174-199. [CrossRef] [PubMed]

23. Yi, J.; Choe, G.; Park, J.; Lee, J.Y. Graphene oxide-incorporated hydrogels for biomedical applications. Polym. J. 2020, 52, 823-837. [CrossRef]

24. Lu, H.; Zhang, S.; Guo, L.; Li, W. Applications of graphene-based composite hydrogels: A review. RSC Adv. 2017, 7, 51008-51020. [CrossRef]

25. Fraga, T.J.M.; Carvalho, M.N.; Ghislandi, M.G.; Motta Sobrinho, M.A. Functionalized graphene-based materials as innovative adsorbents of organic pollutants: A concise overview. Braz. J. Chem. Eng. 2019, 36, 1-31. [CrossRef]

26. Peng, Q.; Zhang, L.; Yan, X.; Zhang, Q.; Zhou, J.; Jiao, T.; Zhao, H. Preparation and adsorption capacity evaluation of graphene oxide-chitosan composite hydrogels. Sci. China Mater. 2015, 58, 811-818.

27. Tang, C.Y.; Yu, P.; Tang, L.S.; Wang, Q.Y.; Bao, R.Y.; Liu, Z.Y.; Yang, M.B.; Yang, W. Tannic acid functionalized graphene hydrogel for organic dye adsorption. Ecotoxicol. Environ. Saf. 2018, 165, 299-306. [CrossRef] [PubMed]

28. Guo, H.; Jiao, T.; Zhang, Q.; Guo, W.; Peng, Q.; Yan, X. Preparation of Graphene Oxide-Based Hydrogels as Efficient Dye Adsorbents for Wastewater Treatment. Nanoscale Res. Lett. 2015, 10, 272. [CrossRef]

29. Mittal, H.; Al Alili, A.; Morajkar, P.P.; Alhassan, S.M. Graphene oxide crosslinked hydrogel nanocomposites of xanthan gum for the adsorption of crystal violet dye. J. Mol. Liq. 2021, 323, 115034. [CrossRef]

30. Sarkar, N.; Sahoo, G.; Swain, S.K. Graphene quantum dot decorated magnetic graphene oxide filled polyvinyl alcohol hybrid hydrogel for removal of dye pollutants. J. Mol. Liq. 2020, 302, 112591. [CrossRef]

31. Xu, J.; Du, P.; Bi, W.; Yao, G.; Li, S.; Liu, H. Graphene oxide aerogels co-functionalized with polydopamine and polyethylenimine for the adsorption of anionic dyes and organic solvents. Chem. Eng. Res. Des. 2020, 154, 192-202. [CrossRef]

32. Chang, Z.; Chen, Y.; Tang, S.; Yang, J.; Chen, Y.; Chen, S.; Li, P.; Yang, Z. Construction of chitosan/polyacrylate/graphene oxide composite physical hydrogel by semi-dissolution/acidification/sol-gel transition method and its simultaneous cationic and anionic dye adsorption properties. Carbohydr. Polym. 2020, 229, 115431. [CrossRef]

33. Ghosh, S.; Kar, P.; Bhandary, N.; Basu, S.; Maiyalagan, T.; Sardar, S.; Pal, S.K. Reduced graphene oxide supported hierarchical flower like manganese oxide as efficient electrocatalysts toward reduction and evolution of oxygen. Int. J. Hydrog. Energy 2017, 42, 4111-4122. [CrossRef]

34. Jiao, T.; Liu, Y.; Wu, Y.; Zhang, Q.; Yan, X.; Gao, F.; Bauer, A.J.P.; Liu, J.; Zeng, T.; Li, B. Facile and Scalable Preparation of Graphene Oxide-Based Magnetic Hybrids for Fast and Highly Efficient Removal of Organic Dyes. Sci. Rep. 2015, 5, 12451. [CrossRef] [PubMed]

35. Pu, N.W.; Chen, C.Y.; Qiu, H.X.; Liu, Y.M.; Song, C.H.; Lin, M.H.; Ger, M. Der Hydrothermal synthesis of N-doped graphene/Fe2O3nanocomposite for supercapacitors. Int. J. Electrochem. Sci. 2018, 13, 6812-6823. [CrossRef]

36. Kwon, Y.H.; Kumar, S.; Bae, J.; Seo, Y. CVD-graphene for low equivalent series resistance in rGO/CVD-graphene/Ni-based supercapacitors. Nanotechnology 2018, 29, 195404. [CrossRef] [PubMed]

37. Fouda, A.N.; Salem, A.; El-Tantawy, F.; Salem, H.; Duraia, E.S.M. Hydrothermal synthesis of high quality graphene nanosheets anchored by uniform and well distributed silicon nanoparticles. Superlattices Microstruct. 2018, 124, 240-247. [CrossRef]

38. Huang, H.H.; De Silva, K.K.H.; Kumara, G.R.A.; Yoshimura, M. Structural evolution of hydrothermally derived reduced graphene oxide. Sci. Rep. 2018, 8, 2-10. [CrossRef]

39. Díez, N.; Śliwak, A.; Gryglewicz, S.; Grzyb, B.; Gryglewicz, G. Enhanced reduction of graphene oxide by high-pressure hydrothermal treatment. RSC Adv. 2015, 5, 81831-81837. [CrossRef]

40. Jiang, X.; Ma, Y.; Li, J.; Fan, Q.; Huang, W. Self-Assembly of Reduced Graphene Oxide into Three-Dimensional Architecture by Divalent Ion Linkage. J. Phys. Chem. C 2010, 114, 22462-22465. [CrossRef]

41. Fan, J.; Shi, Z.; Lian, M.; Li, H.; Yin, J. Mechanically strong graphene oxide/sodium alginate/polyacrylamide nanocomposite hydrogel with improved dye adsorption capacity. J. Mater. Chem. A 2013, 1, 7433-7443. [CrossRef]

42. Xiao, D.; He, M.; Liu, Y.; Xiong, L.; Zhang, Q.; Wei, L. Strong alginate/reduced graphene oxide composite hydrogels with enhanced dye adsorption performance. Polym. Bull. 2020, 77, 6609-6623. [CrossRef]

43. E, T.; Ma, Z.; Yang, S.; Li, Y.; Ma, D.; Xing, Z.; Li, Y. Enhanced electrical conductivity of TiO2/graphene: The role of introducing Ca2+. J. Alloys Compd. 2020, 827, 154280. [CrossRef]

44. Serrano-Aroca, Á.; Deb, S. Synthesis of irregular graphene oxide tubes using green chemistry and their potential use as reinforcement materials for biomedical applications. PLoS ONE 2017, 12, 1-14. [CrossRef] [PubMed]

45. Park, S.; Lee, K.S.; Bozoklu, G.; Cai, W.; Nguyen, S.B.T.; Ruoff, R.S. Graphene oxide papers modified by divalent ions-Enhancing mechanical properties via chemical cross-linking. ACS Nano 2008, 2, 572-578. [CrossRef] [PubMed]

46. Zhang, T.; Zhu, G.-Y.; Yu, C.-H.; Xie, Y.; Xia, M.-Y.; Lu, B.-Y.; Fei, X.; Peng, Q. The UV absorption of graphene oxide is size-dependent: Possible calibration pitfalls. Microchim. Acta 2019, 186, 207. [CrossRef] [PubMed]

47. Saha, P.; Pyne, D.K.; Ghosh, S.; Banerjee, S.; Das, S.; Ghosh, S.; Dutta, P.; Halder, A. Effect of an anionic surfactant (SDS) on the photoluminescence of graphene oxide (GO) in acidic and alkaline medium. RSC Adv. 2018, 8, 584-595. [CrossRef] 
48. Mautner, A.; Kobkeatthawin, T.; Mayer, F.; Plessl, C.; Gorgieva, S.; Kokol, V.; Bismarck, A. Rapid Water Softening with TEMPOOxidized/Phosphorylated Nanopapers. Nanomaterials 2019, 9, 136. [CrossRef] [PubMed]

49. Feng, G.; Liu, C.-W.; Zeng, Z.; Hou, G.-L.; Xu, H.-G.; Zheng, W.-J. Initial hydration processes of magnesium chloride: Size-selected anion photoelectron spectroscopy and ab initio calculations. Phys. Chem. Chem. Phys. 2017, 19, 15562-15569. [CrossRef]

50. Hunter, R.J. Electrokinetics and the zeta potential. In Foundations of Colloid Science 2; University Press: New York, NY, USA, 2001; pp. 376-377.

51. Zhao, D.; Yu, L.; Liu, D. Ultralight graphene/carbon nanotubes aerogels with compressibility and oil absorption properties. Materials 2018, 11, 641. [CrossRef]

52. Luo, Y.; Jiang, S.; Xiao, Q.; Chen, C.; Li, B. Highly reusable and superhydrophobic spongy graphene aerogels for efficient oil/water separation. Sci. Rep. 2017, 7, 1-10. [CrossRef]

53. Whitby, R.L.D. Chemical control of graphene architecture: Tailoring shape and properties. ACS Nano 2014, 8, 9733-9754. [CrossRef]

54. Jin, M.; Jiao, N.; Zhang, C.X.; Xiao, H.P.; Zhang, K.W.; Sun, L.Z. Reduction mechanism of hydroxyl group from graphene oxide with and without-NH2 agent. Phys. B Condens. Matter 2015, 477, 70-74. [CrossRef]

55. Zhao-Karger, Z.; Fichtner, M. Beyond Intercalation Chemistry for Rechargeable Mg Batteries: A Short Review and Perspective. Front. Chem. 2019, 6, 656. [CrossRef] [PubMed]

56. Ikram, M.; Raza, A.; Imran, M.; Ul-Hamid, A.; Shahbaz, A.; Ali, S. Hydrothermal synthesis of silver decorated reduced graphene oxide (rGO) nanoflakes with effective photocatalytic activity for wastewater treatment. Nanoscale Res. Lett. 2020, 15, 1-11. [CrossRef] [PubMed]

57. Bharath, G.; Anwer, S.; Mangalaraja, R.V.; Alhseinat, E.; Banat, F.; Ponpandian, N. Sunlight-Induced photochemical synthesis of Au nanodots on $\alpha$-Fe2O3@Reduced graphene oxide nanocomposite and their enhanced heterogeneous catalytic properties. Sci. Rep. 2018, 8, 1-14. [CrossRef] [PubMed]

58. Radoń, A.; Włodarczyk, P.; Łukowiec, D. Structure, temperature and frequency dependent electrical conductivity of oxidized and reduced electrochemically exfoliated graphite. Phys. E Low Dimens. Syst. Nanostructures 2018, 99, 82-90. [CrossRef]

59. Wang, S.; Dong, Y.; He, C.; Gao, Y.; Jia, N.; Chen, Z.; Song, W. The role of sp2/sp3 hybrid carbon regulation in the nonlinear optical properties of graphene oxide materials. RSC Adv. 2017, 7, 53643-53652. [CrossRef]

60. Peng, W.; Han, G.; Huang, Y.; Cao, Y.; Song, S. Insight the effect of crystallinity of natural graphite on the electrochemical performance of reduced graphene oxide. Results Phys. 2018, 11, 131-137. [CrossRef]

61. Cui, P.; Lee, J.; Hwang, E.; Lee, H. One-pot reduction of graphene oxide at subzero temperatures. Chem. Commun. 2011, 47, 12370-12372. [CrossRef]

62. Thommes, M.; Kaneko, K.; Neimark, A.V.; Olivier, J.P.; Rodriguez-Reinoso, F.; Rouquerol, J.; Sing, K.S.W. Physisorption of gases, with special reference to the evaluation of surface area and pore size distribution (IUPAC Technical Report). Pure Appl. Chem. 2015, 87, 1051-1069. [CrossRef]

63. Guo, F.; Creighton, M.; Chen, Y.; Hurt, R.; Külaots, I. Porous structures in stacked, crumpled and pillared graphene-based 3D materials. Carbon N. Y. 2014, 66, 476-484. [CrossRef]

64. Wang, C.; Zhou, J.; Du, F. Synthesis of Highly Reduced Graphene Oxide for Supercapacitor. J. Nanomater. 2016, 2016 , 1-7. [CrossRef]

65. Gadipelli, S.; Guo, Z.X. Graphene-based materials: Synthesis and gas sorption, storage and separation. Prog. Mater. Sci. 2015, 69, 1-60. [CrossRef]

66. Ren, H.; Shi, X.; Zhu, J.; Zhang, Y.; Bi, Y.; Zhang, L. Facile synthesis of N-doped graphene aerogel and its application for organic solvent adsorption. J. Mater. Sci. 2016, 51, 6419-6427. [CrossRef]

67. Cheng, H.; Xue, H.; Zhao, G.; Hong, C.; Zhang, X. Preparation, characterization, and properties of graphene-based composite aerogels via in situ polymerization and three-dimensional self-assembly from graphene oxide solution. RSC Adv. 2016, 6, 78538-78547. [CrossRef]

68. Ren, L.; Hui, K.N.; Hui, K.S.; Liu, Y.; Qi, X.; Zhong, J.; Du, Y.; Yang, J. 3D hierarchical porous graphene aerogel with tunable meso-pores on graphene nanosheets for high-performance energy storage. Sci. Rep. 2015, 5, 14229. [CrossRef] [PubMed]

69. Yang, Y.; Song, S.; Zhao, Z. Graphene oxide (GO) / polyacrylamide (PAM) composite hydrogels as efficient cationic dye adsorbents. Colloids Surfaces A Physicochem. Eng. Asp. 2017, 513, 315-324. [CrossRef]

70. Baig, N.; Ihsanullah; Sajid, M.; Saleh, T.A. Graphene-based adsorbents for the removal of toxic organic pollutants: A review. J. Environ. Manag. 2019, 244, 370-382. [CrossRef]

71. Sun, Y.; Yu, F.; Li, C.; Dai, X.; Ma, J. Nano-/Micro-confined Water in Graphene Hydrogel as Superadsorbents for Water Purification. Nano Micro Lett. 2020, 12, 2. [CrossRef]

72. Yu, F.; Sun, Y.; Yang, M.; Ma, J. Adsorption mechanism and effect of moisture contents on ciprofloxacin removal by threedimensional porous graphene hydrogel. J. Hazard. Mater. 2019, 374, 195-202. [CrossRef]

73. Özer, A.; Dursun, G. Removal of methylene blue from aqueous solution by dehydrated wheat bran carbon. J. Hazard. Mater. 2007, 146, 262-269. [CrossRef]

74. Jiang, D.; Deng, R.; Li, G.; Zheng, G.; Guo, H. Constructing an ultra-adsorbent based on the porous organic molecules of noria for the highly efficient adsorption of cationic dyes. RSC Adv. 2020, 10, 6185-6191. [CrossRef] 
75. Thakur, S.; Arotiba, O. Synthesis, characterization and adsorption studies of an acrylic acid-grafted sodium alginate-based TiO 2 hydrogel nanocomposite. Adsorpt. Sci. Technol. 2018, 36, 458-477. [CrossRef]

76. Cheng, C.; Liu, Z.; Li, X.; Su, B.; Zhou, T.; Zhao, C. Graphene oxide interpenetrated polymeric composite hydrogels as highly effective adsorbents for water treatment. RSC Adv. 2014, 4, 42346-42357. [CrossRef]

77. Rudzinski, W.; Plazinski, W. Kinetics of Solute Adsorption at Solid/Solution Interfaces: On the Special Features of the Initial Adsorption Kinetics. Langmuir 2008, 24, 6738-6744. [CrossRef] [PubMed]

78. Zheng, A.L.T.; Phromsatit, T.; Boonyuen, S.; Andou, Y. Synthesis of silver nanoparticles/porphyrin/reduced graphene oxide hydrogel as dye adsorbent for wastewater treatment. Flat Chem. 2020, 23, 100174.

79. Hernandez-Martínez, A.R.; Lujan-Montelongo, J.A.; Silva-Cuevas, C.; Mota-Morales, J.D.; Cortez-Valadez, M.; de Jesus RuízBaltazar, Á.; Cruz, M.; Herrera-Ordonez, J. Swelling and methylene blue adsorption of poly $(\mathrm{N}, \mathrm{N}$-dimethylacrylamide-co-2hydroxyethyl methacrylate) hydrogel. React. Funct. Polym. 2018, 122, 75-84.

80. Wang, R.; Zhang, X.; Zhu, J.; Bai, J.; Gao, L.; Liu, S.; Jiao, T. Facile preparation of self-assembled chitosan-based composite hydrogels with enhanced adsorption performances. Colloids Surfaces A Physicochem. Eng. Asp. 2020, 598, 124860. [CrossRef]

81. Wang, R.; Yu, Q.; He, Y.; Bai, J.; Jiao, T.; Zhang, L.; Bai, Z.; Zhou, J.; Peng, Q. Self-assembled polyelectrolyte-based composite hydrogels with enhanced stretchable and adsorption performances. J. Mol. Liq. 2019, 294, 111576. [CrossRef]

82. Dai, H.; Huang, Y.; Huang, H. Eco-friendly polyvinyl alcohol/carboxymethyl cellulose hydrogels reinforced with graphene oxide and bentonite for enhanced adsorption of methylene blue. Carbohydr. Polym. 2018, 185, 1-11. [CrossRef]

83. Sarkar, N.; Sahoo, G.; Swain, S.K. Nanoclay sandwiched reduced graphene oxide filled macroporous polyacrylamide-agar hybrid hydrogel as an adsorbent for dye decontamination. Nano Struct. Nano Objects 2020, 23, 100507. [CrossRef]

84. Soleimani, K.; Tehrani, A.D.D.; Adeli, M. Bioconjugated graphene oxide hydrogel as an effective adsorbent for cationic dyes removal. Ecotoxicol. Environ. Saf. 2018, 147, 34-42. [CrossRef]

85. Zhang, Y.; Li, K.; Liao, J. Facile synthesis of reduced-graphene-oxide/rare-earth-metal-oxide aerogels as a highly efficient adsorbent for Rhodamine-B. Appl. Surf. Sci. 2020, 504, 144377. [CrossRef]

86. Pradhan, A.C.; Paul, A.; Rao, G.R. Sol-gel-cum-hydrothermal synthesis of mesoporous Co-Fe@Al2O3-MCM-41 for methylene blue remediation. J. Chem. Sci. 2017, 129, 381-395. [CrossRef]

87. Belhanafi, H.; Bakhti, A.; Benderdouche, N. Study of interactions between rhodamine B and a beidellite-rich clay fraction. Clay Miner. 2020, 55, 194-202. [CrossRef]

88. Bayomie, O.S.; Kandeel, H.; Shoeib, T.; Yang, H.; Youssef, N.; El-Sayed, M.M.H. Novel approach for effective removal of methylene blue dye from water using fava bean peel waste. Sci. Rep. 2020, 10, 7824. [CrossRef] [PubMed]

89. Saghanejhad Tehrani, M.; Zare-Dorabei, R. Highly efficient simultaneous ultrasonic-assisted adsorption of methylene blue and rhodamine B onto metal organic framework MIL-68(Al): Central composite design optimization. RSC Adv. 2016, 6, 27416-27425. [CrossRef] 